University of Louisville

ThinkIR: The University of Louisville's Institutional Repository

Electronic Theses and Dissertations

$5-2017$

\title{
Effect of high cationic flocculant on anaerobic digestion of municipal wastewater.
}

Prathap D. John

University of Louisville

Follow this and additional works at: https://ir.library.louisville.edu/etd

Part of the Environmental Engineering Commons, and the Other Chemical Engineering Commons

\section{Recommended Citation}

John, Prathap D., "Effect of high cationic flocculant on anaerobic digestion of municipal wastewater." (2017). Electronic Theses and Dissertations. Paper 2815.

https://doi.org/10.18297/etd/2815

This Master's Thesis is brought to you for free and open access by ThinkIR: The University of Louisville's Institutional Repository. It has been accepted for inclusion in Electronic Theses and Dissertations by an authorized administrator of ThinkIR: The University of Louisville's Institutional Repository. This title appears here courtesy of the author, who has retained all other copyrights. For more information, please contact thinkir@louisville.edu. 
By

Prathap Daniel John

B.S, University of Louisville, 2006

\author{
A Thesis \\ Submitted to the Faculty of the \\ University of Louisville \\ J.B. Speed School of Engineering \\ as Partial Fulfillment of the Requirements \\ for the Professional Degree
}

MASTER OF ENGINEERING

Department of Chemical Engineering 

EFFECT OF HIGH CATIONIC FLOCCULANT ON ANAEROBIC DIGESTION OF MUNICIPAL WASTEWATER

Submitted by:

Prathap Daniel John

A Thesis Approved On

(Date)

by the Following Reading and Examination Committee:

Dr. R. Eric Berson, Thesis Director

Dr. James Watters

Dr. Thomas Rockaway 


\section{ACKNOWLEDGEMENTS}

I would like to thank the Conn Center for Renewable Energy Research and my research advisor Dr. Jagannadh Satyavolu for the opportunity to work on this project and the endless guidance and support given to me.

I would like to express my immense gratitude to my thesis director Dr. Eric Berson for helping and guiding me in the completion of my thesis.

I would like to thank Dr. James Watters for his guidance and support throughout graduate school.

I would like to thank MSD for funding this project and Robert Bates for providing the materials and the support given for this project.

I would like to thank Dr. Rockaway for being on my committee and the valuable inputs he has given to me on the thesis.

I would also like to take this opportunity to thank my wife and my parents for their love, support and encouragement throughout graduate school. 


\begin{abstract}
Anaerobic digestion (AD) of municipal sludge is a widely used stabilization process at municipal wastewater treatment plants. It is highly effective in reducing sludge volume and produces methane gas which is used as fuel in the wastewater plant. Following digestion sludge is sent to a centrifuge to separate the solids from the liquids. Louisville MSD adds flocculent to material in the centrifuge to better coagulate the solids, thereby aiding in separation of the solids from the liquids. The potential for further $\mathrm{AD}, \mathrm{COD}$ reduction, and methane generation of the liquid effluent from the centrifuge was unknown, particularly in regards to whether the flocculant could impact AD. Previous studies on flocculent have been non-conclusive.
\end{abstract}

Respirometery tests for biogas production, theoretical biogas production based on COD content, and COD reduction measurements all indicate that trace amounts of polymer left in the wastewater after centrifugation, in the range of $2.5 \mathrm{mg} / \mathrm{L}-10 \mathrm{mg} / \mathrm{L}$, can hinder anaerobic digestion of the wastewater. There was no effect on biogas quality (methane content in the biogas) due to trace amounts of polymer, in the $1 \mathrm{mg} / \mathrm{L}-10 \mathrm{mg} / \mathrm{L}$ range, in the wastewater. UV Vis can be used to indirectly measure anaerobic degradation of the polymer in the wastewater based on the clarity of the wastewater.

This study recommends that Louisville MSD should minimize the use of polymer to increase the anaerobic digestion potential ie. increase the amount of methane generated from the liquid stream after centrifugation. 


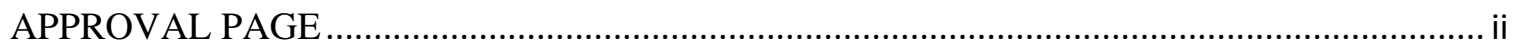

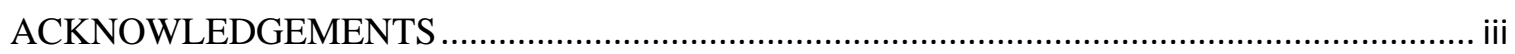

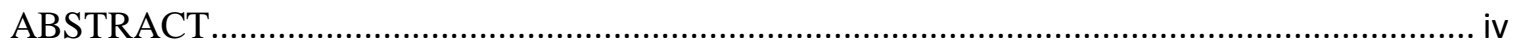

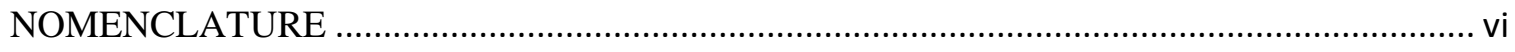

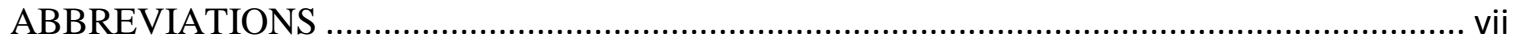

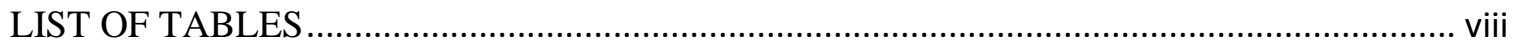

LIST OF FIGURES ……………………………………………………………….... ix

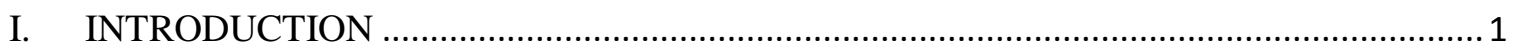

II. REVIEW OF RELATED LITERATURE …………………......................................

A. ANAEROBIC DIGESTION IN MUNICIPAL WASTE WATER SYSTEMS ....................5

B. EFFECT OF POLYMER ON ANAEROBIC DIGESTION ...........................................15

C. DETECTION AND QUANTIFICATION OF RESIDUAL POLYACRYLAMIDE

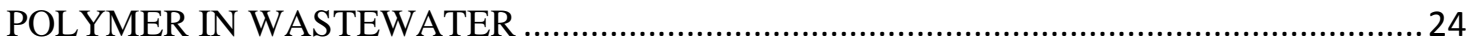

III. EXPERIMENTAL ............................................................................................

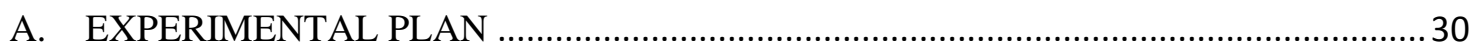

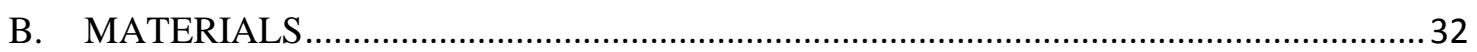

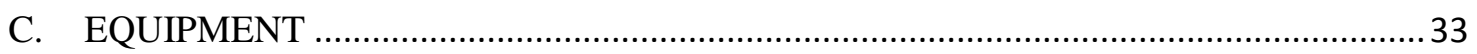

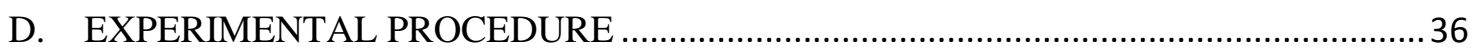

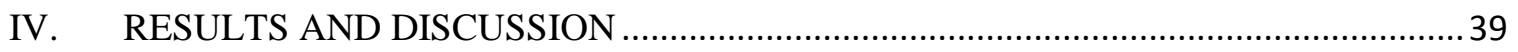

A. RESPIROMETER EXPERIMENT RESULTS ………………......................................

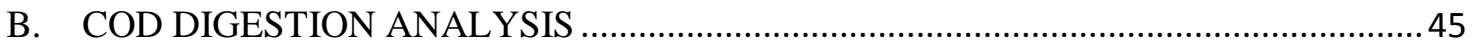

C. THEORETICAL BIOGAS PRODUCTION COMPARISON ………………………....46

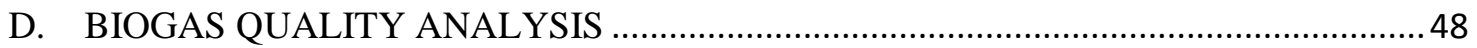

E. POLYMER DETECTION IN WASTEWATER ……………………........................49

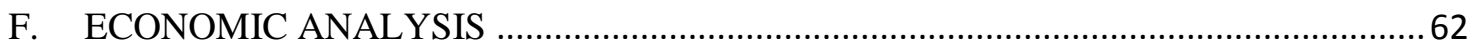

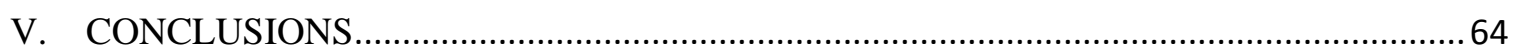

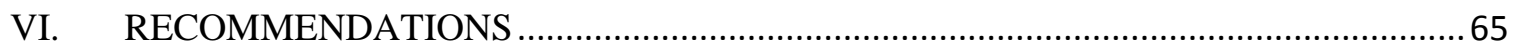

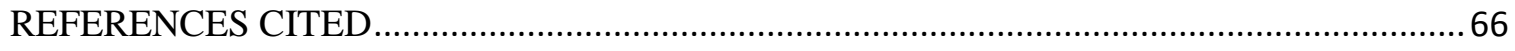

VITA 


\section{NOMENCLATURE}

$$
\begin{array}{ll}
\% & =\text { percent } \\
\mathrm{Lbs} & =\text { pounds (unit of mass) } \\
\mathrm{Kg} & =\text { Kilograms (unit of mass) } \\
\mathrm{pH} & =\text { potential of hydrogen } \\
{ }^{\circ} \mathrm{C} & =\text { Celsius (unit of temperature) } \\
\mathrm{W} / \mathrm{v} & =\text { weight per volume } \\
\mathrm{nm} & =\text { nanometer } \\
\mathrm{mg} / \mathrm{L} & =\text { milligram per Liter } \\
\mathrm{rpm} & =\text { rates per minute } \\
\mathrm{KWhrs} & =\text { Kilo Watt hours } \\
\mathrm{Scf} & =\text { standard cubic feet (unit of volume) } \\
\mathrm{BTU} & =\text { British Thermal Unit (unit of heat) } \\
\mathrm{MW} & =\text { Megawatt (unit of power) } \\
\mathrm{Gal} & =\text { gallon (unit of volume) }
\end{array}
$$




\section{ABBREVIATIONS}

\begin{tabular}{|c|c|}
\hline $\mathrm{AD}$ & Anaerobic Digestion \\
\hline COD & Chemical Oxygen Demand \\
\hline DI & Deionized \\
\hline GC & Gas Chromatography \\
\hline HRT & Hydraulic Retention Time \\
\hline MSD & Municipal Sewer District (Louisville) \\
\hline MSW & Municipal Solid waste \\
\hline OLR & Organic Loading Rate \\
\hline PAM & Polyacrylamide \\
\hline SEC & Size Exclusion Chromatography \\
\hline TCD & Thermal Conductivity Detector \\
\hline TDS & Total Dissolved Solids \\
\hline TS & Total Solids \\
\hline TSS & Total Suspended Solids \\
\hline USGS & United States Geological Survey \\
\hline UV-Vis & Ultraviolet-Visible Spectroscopy \\
\hline VS & Volatile Solids \\
\hline
\end{tabular}




\section{LIST OF TABLES}

Table I - DIFFERENT BOTTLE REACTOR CONDITIONS FOR ANAEROBIC DIGESTION RESPIROMETER EXPERIMENT .

Table II - SUMMARY OF DISSOLVED SOLIDS LOST FROM THE WASTEWATER FOLLOWING ADDITION OF POLYMER 39

Table III - BIOGAS PRODUCTION VOLUMES FROM DIFFERENT PAM CONCENTRATIONS 41

Table IV - BIOGAS PRODUCTION AS A FUNCTION OF PAM CONCENTRATION. 43

Table V - SUMMARY OF COD REDUCTION AS A FUNCTION OF PAM CONCENTRATION.

Table VI - THEORETICAL BIOGAS PRODUCTION AS A FUNCTION OF PAM BASED ON

COD LOADING. 47

Table VII - COMPARISON OF ACTUAL AND THEORETICAL BIOGAS VOLUME ...........47

Table VIII - METHANE AND CARBON DIOXIDE QUALITY IN THE BIOGAS .49

Table IX - ABSORBANCE VALUE COMPARISON FOR PRE DIGESTION AND POST DIGESTION SAMPLES FOR 10\% AND 20\% DILUTION 60

Table $\mathrm{X}$ - CONCENTRATION OF AMMONIA BEFORE AND AFTER DIGESTION 61

Table XI - THEORETICAL ELECTRICITY GENERATION VALUES AS A FUNCTION OF PAM CONCENTRATION 62

Table XII - ANNUAL REVENUES FROM ELECTRICITY GENERATION .63 


\section{LIST OF FIGURES}

Figure 1 - Four stages of Anaerobic Digestion

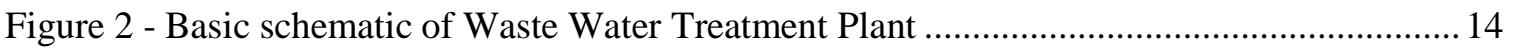

Figure 3 - Gas Chromatograph used for Biogas Analysis (SRI 8610C) ………............................ 34

Figure 4 - Lab scale respirometer for anaerobic digestion (PF-8000 model) ................................35

Figure 5 - UV Vis Spectrometer used for polymer detection (Lambda 950 model)...................... 36

Figure 6 - Average biogas production as a function of time from the three different respirometry

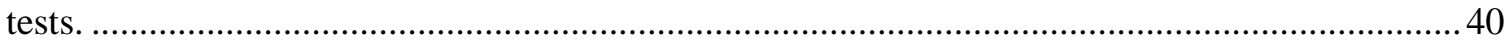

Figure 7 - Biogas production as a function of PAM concentration .......................................... 42

Figure 8 - Absorbance data for pre digestion wastewater samples diluted by $90 \%$ (1 part

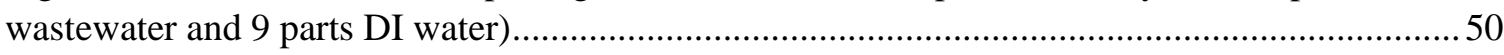

Figure 9 - Absorbance data for post digestion wastewater samples diluted by $90 \%$ (1 part wastewater and 9 parts DI water)....................................................................................... 51

Figure 10 - Absorbance data for pre digestion wastewater samples diluted by $80 \%$ ( 2 parts

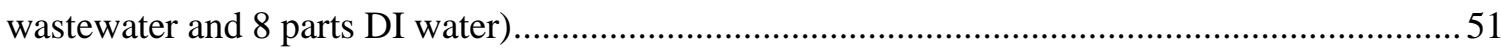

Figure 11 - Absorbance data for post digestion wastewater samples diluted by $80 \%$ ( 2 parts

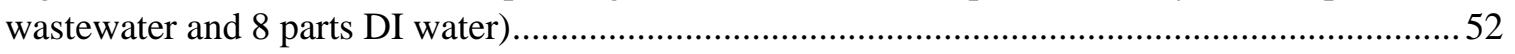

Figure 12 - Comparison of pre and post digestion absorbance at $1 \mathrm{mg} / \mathrm{L}$ for $90 \%$ dilution ...........53

Figure 13 - Comparison of pre and post digestion absorbance at $2.5 \mathrm{mg} / \mathrm{L}$ for $90 \%$ dilution ........53

Figure 14 - Comparison of pre and post digestion absorbance at $5 \mathrm{mg} / \mathrm{L}$ for $90 \%$ dilution ...........54

Figure 15 - Comparison of pre and post digestion absorbance at $7.5 \mathrm{mg} / \mathrm{L}$ for $90 \%$ dilution ........55

Figure 16 - Comparison of pre and post digestion absorbance at $10 \mathrm{mg} / \mathrm{L}$ for $90 \%$ dilution .........55

Figure 17 - Comparison of pre and post digestion absorbance at $90 \%$ dilution for no polymer

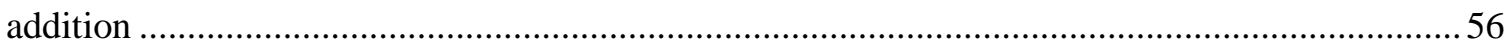

Figure 18 - Comparison of pre and post digestion absorbance at $1 \mathrm{mg} / \mathrm{L}$ for $80 \%$ dilution ..........57

Figure 19 - Comparison of pre and post digestion absorbance at $2.5 \mathrm{mg} / \mathrm{L}$ for $80 \%$ dilution ........57

Figure 20 - Comparison of pre and post digestion absorbance at $5 \mathrm{mg} / \mathrm{L}$ for $80 \%$ dilution ...........58

Figure 21 - Comparison of pre and post digestion absorbance at $7.5 \mathrm{mg} / \mathrm{L}$ for $80 \%$ dilution ........58

Figure 22 - Comparison of pre and post digestion absorbance at $10 \mathrm{mg} / \mathrm{L}$ for $80 \%$ dilution ........ 59

Figure 23 - Comparison of pre and post digestion absorbance at $80 \%$ dilution for no polymer

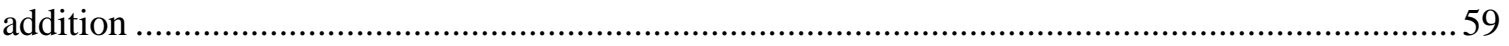




\section{INTRODUCTION}

Anaerobic digestion is a series of biological processes, carried out in the absence of air, where microorganisms (bacteria) break down biodegradable material in the substrate. The anaerobic treatment process has been recognized as one of the most successful technologies in the treatment of municipal solid waste. Anaerobic digestion has become fully accepted as a proven and an even preferred method for the intensive biodegradation phase of organic fractions derived from municipal solid waste.

Advantages associated with anaerobic digestion of municipal solid waste (or sludge) include reduction of the amount of waste landfilled, stabilization of organic material before final disposal to reduce future environmental impacts, and energy recovery.

For the anaerobic treatment process, the sludge is first collected from the primary and the secondary clarifiers in wastewater treatment plants and thickened to reduce water content. This sludge is then sent to the anaerobic digesters where it is digested to reduce organic matter, eliminate odor causing material, and kill pathogens. The stabilized sludge is then conditioned with flocculant polymers prior to dewatering.

Water soluble flocculants are used extensively in wastewater treatment plants (WWTP) worldwide to enhance settling, thickening, and dewatering processes in wastewater treatment. Polymer conditioning destabilizes colloidal materials and causes small particles to agglomerate into larger flocs that easily settle.

Flocculation is the action of polymers to form bridges between flocs and bind the particles into large agglomerates or clumps. Bridging occurs when segments of the 
polymer chain adsorb on different particles, which helps the particles to aggregate. Depending on the charge and characteristics of the solid particles, the optimum polymer can be cationic, anionic, or non-ionic. Solid waste in municipal wastewater is generally negative in charge, therefore a cationic polymer is introduced to neutralize the negative charge. Once suspended particles are flocculated into larger particles, they can usually be separated from the liquid by sedimentation, provided there is a sufficient density difference between the water and the particles.

Polymer use in wastewater treatment plants continue to increase every year with the polymer market projected to grow 5\% annually. Typical doses of polymer used in the conditioning of sludge are in the range of 10 to $20 \mathrm{lbs}$ of active polymer per ton of dry solids. So, it is possible that polymer can represent $0.5 \%$ to $1 \%$ of the dry mass of sludge in wastewater treatment plants that use polymer. Although this seems like a small fraction, the polymer that could be attached to the conditioned sludge can amount up to $10 \mathrm{~kg}$ per ton of dry solids.

Concerns exist on the fate and effect of the polymers after their use in wastewater treatment plants. The polymer may remain in the aqueous phase and pass through as treated effluents or it may be adsorbed onto the surface of the solids and pass through as the final sludge product. It is highly unlikely that the polymer will pass through as entirely in either the liquid or solid flow, but rather have some fraction within each flow. It is important to determine the amount of polymer that passes along in the liquid and solid phase. If the quantification of the polymer indicates that majority of the polymer passes along with the conditioned solids, then the effect of the polymers that passes along 
with the liquid stream on biological wastewater treatment process like anaerobic digestion has to be determined.

Previous studies have reported conflicting results. One study noted that methane production and volatile solids destruction ratio were reduced in an anaerobic digested wastewater sludge in the presence of an organic polymer (Gossett, 1978). Another study found that the synthetic polymer not only has no inhibition effects to biomass activity, but it could also enhance the metabolite transfer rate and reduce the inhibition of acetogenic and methanogenic bacteria (El-Mamouni, 1998). This discrepancy in results leads to the present investigation of the role of polymer flocculant on anaerobic digestion efficiency of wastewater.

\section{$\underline{\text { Thesis Objectives }}$}

1. Determine the effect of residual polymer present in wastewater on anaerobic digestion. Tests were performed to determine whether the flocculant polymer in the wastewater has any effect on the efficiency of the anaerobic digestion process. Respirometry tests were run with five different concentrations of polymer in wastewater to monitor the biogas production levels. COD tests were performed on the wastewater samples dosed with different concentrations of polymer. Theoretical biogas production was also compared to actual biogas production. The respirometry tests helped quantify the volume of biogas produced. GC analysis was used to determine the biogas quality (\% of methane) for the different wastewater samples dosed with polymer. 
2. Quantify polymer in the centrate. The UV-Vis analysis method is a straightforward and simple method to measure the amount of polymer concentration in wastewater. The detection and quantification of polymer was performed via the UV-Vis method. 


\section{REVIEW OF RELATED LITERATURE}

\section{A. ANAEROBIC DIGESTION IN MUNICIPAL WASTE WATER SYSTEMS}

Anaerobic digestion (AD) is a series of biological processes, carried out in the absence of oxygen, where microorganisms (bacteria) break down biodegradable material in the substrate (municipal solid waste). This occurs in naturally existing anaerobic systems such as marshes, sediments, wetlands, and the digestive tracts of ruminants. The advantages associated with $\mathrm{AD}$ of municipal solid waste (MSW) is that it reduces the amount of waste being landfilled, stabilizes organic material before disposal to reduce future environmental impacts, and recover energy. One of the end products of anaerobic digestion is biogas which consists of methane (50 to $80 \%$ ), carbon dioxide (20 to $50 \%$ ) and trace amounts of hydrogen sulfide, ammonia and nitrogen. (Igoni, Ayotamuno, 2008). Methane is a valuable fuel which can be captured and used to power the digester or fuel a generator to produce electricity for the other units in the facility, or burned for heat. AD technologies differ based on the type of waste feedstock.

\section{AD Mechanism}

Anaerobic treatment processes occur in the absence of oxygen. Microorganisms called anaerobes biochemically convert organic substrates present in the wastewater into methane and carbon dioxide, hydrogen sulfide, ammonia and nitrogen. Anaerobic digestion takes place as a series of metabolic interactions between various groups of microorganisms. It occurs in four stages: hydrolysis, acidification, acetogenesis, and methanogenesis (Young and Cowan, 2004). The initial group of microorganisms secrete 
enzymes which hydrolyzes the polymeric materials into monomers such as glucose and amino acids. The monomers are then converted to higher volatile fatty acids, $\mathrm{H}_{2}, \mathrm{CO}_{2}$ and acetic acid by a different group of microorganisms known as the acetogenic bacteria. The last group of bacteria, also known as methanogenic bacteria, convert the $\mathrm{H}_{2}, \mathrm{CO}_{2}$ and acetate to $\mathrm{CH}_{4}$ (Ghorbanian, 2014).

The four stages are shown in FIGURE 1 and discussed below.

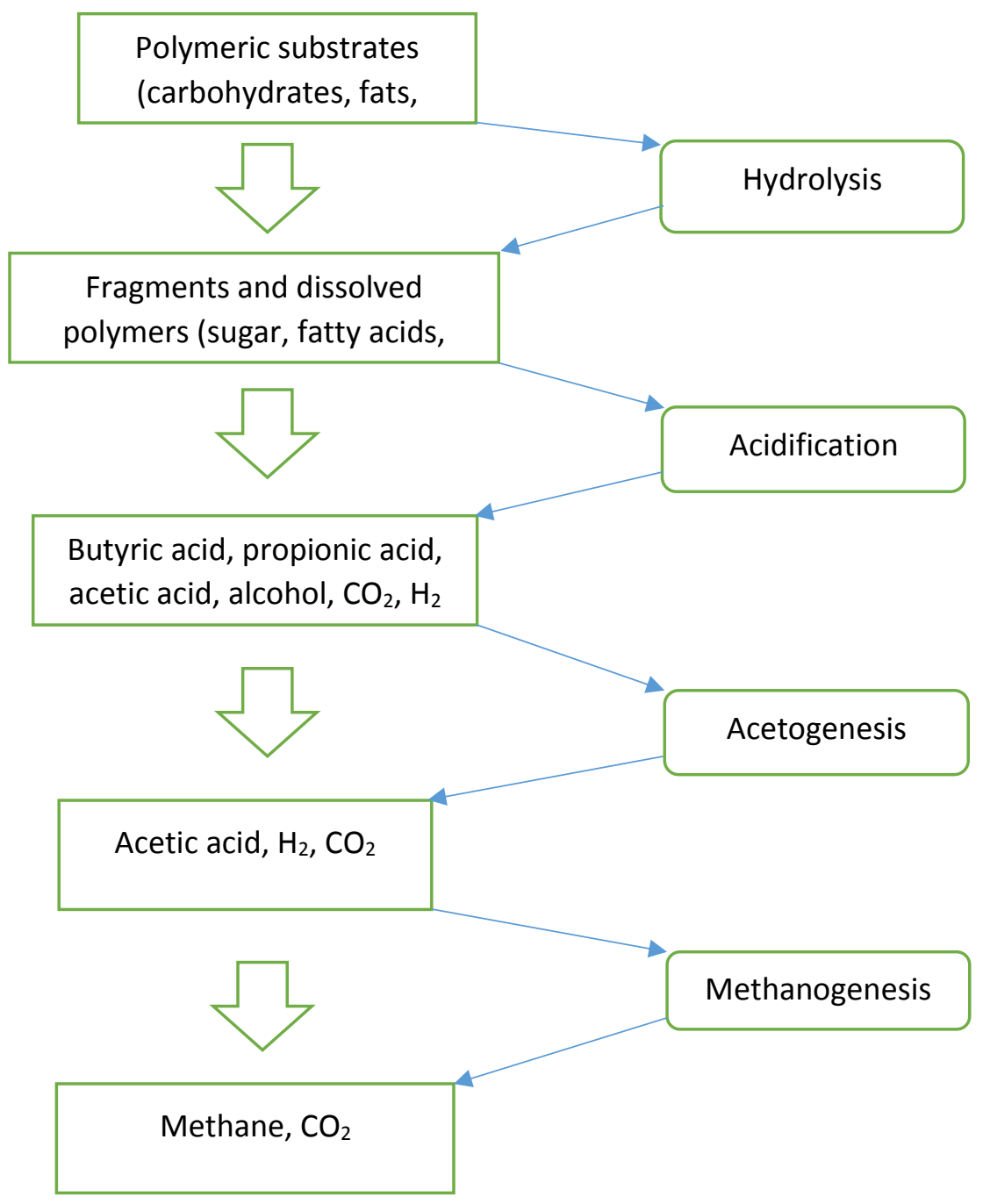

FIGURE 1 - Four stages of Anaerobic Digestion 


\section{$1.1 \underline{\text { Hydrolysis }}$}

During hydrolysis complex undissolved organic substances such as fats, cellulose and proteins are converted into smaller, soluble components like long-chain fatty acids, simple sugars, and amino acids, by extracellular enzymes. This process occurs relatively slowly and the process speed is controlled by the $\mathrm{pH}$ value, the biomass concentration, and the presence of organic substrate. The ideal $\mathrm{pH}$ value is approximately 6 (Young and Cowan, 2004). The microorganisms obtain little to no energy during the reaction which results in a low biomass yield.

\subsection{Acidification}

Next is the acidification step where an oxidation-reduction process occurs in which the acid former bacteria converts the dissolved polymers into one or more intermediates such as fatty acids, butyric acid, propionic acid, acetic acid, alcohols, carbon dioxide, and oxygen. The products produced in this stage depends on the type of bacteria, the organic substrate, and the process conditions. Two types of acid former bacteria are syntrophobacter wolinii, a propionate decomposer and sytrophomonos wolfei, a butyrate decomposer. Other acid formers are clostridium, peptococcus anerobus, lactobacillus, and actinomyces (Young and Cowan, 2004). Acid former bacteria in general have a high $\mathrm{pH}$ tolerance. The reaction occurs up to a $\mathrm{pH}$ value of 4 .

$$
\text { Organics } \rightarrow \text { Intermediates }+\mathrm{CO}_{2}+\mathrm{H}_{2} \mathrm{O}+\mathrm{H}_{2}+\text { Biomass }
$$




\subsection{Acetogenesis}

In the acetogenesis phase the intermediates formed in the acidification step are converted into carbon dioxide, hydrogen, and acetic acid. In some situations, hydrogen and carbon dioxide can be converted to acetate through the action of homo-acetogenic microorganisms. The hydrogen produced during fermentation and acetogenesis is typically converted to methane through hydrogenotrophic methanogenesis.

Organic intermediates $\rightarrow$ acetic acid $+\mathrm{CO}_{2}+\mathrm{H}_{2} \mathrm{O}+\mathrm{H}_{2}+$ biomass

\subsection{Methanogenesis}

In the final stage which is the methanogenesis stage, methane former bacteria (also known as methanogens) produce biogas in two ways: by means of cleavage of the acetic acid molecules to generate carbon dioxide and methane or by the reduction of carbon dioxide with hydrogen to form methane. Methane production is higher from carbon dioxide reduction but limited hydrogen concentration in digesters results in the acetate reaction being the primary producer of methane (Verma, 2002).

This stage involves two physiologically different groups of methane-forming microorganisms. Acetoclastic methanogens decarboxylate acetic acid to form methane and carbon dioxide as follows:

Acetic acid $\rightarrow \mathrm{CH}_{4}+\mathrm{CO}_{2}+$ biomass 
The hydrogen released as a metabolic product of fermentation and acetogenesis is converted by autotrophic oxidation of hydrogen, or hydrogenotrophic methanogenesis to form methane as follows:

$$
8 \mathrm{H}+\mathrm{CO}_{2} \rightarrow \mathrm{CH}_{4}+2 \mathrm{H}_{2} \mathrm{O}+\text { biomass }
$$

The response of the different groups of anaerobic microorganisms depends on the type of substrate components. Inhibition of any one of the intermediate reactions can obstruct the entire degradation process.

\section{Advantages of Anaerobic Digestion}

The two popular methods of treating wastewater are aerobic and anaerobic treatment. As the names suggests the aerobic process occurs in the presence of oxygen whereas the anaerobic process occurs in the absence of oxygen. The advantages of anaerobic digestion over aerobic digestion are: (a) There is no oxygen requirement. The aerobic process requires a continuous supply of oxygen for it to occur. The oxygen supply increases the expenses and the energy requirements for the aerobic process which is not needed for the anaerobic process (Rapport, 2008). (b) The sludge produced after anaerobic digestion is far less in volume compared to the sludge produced by aerobic digestion. During aerobic treatment, the microorganisms derive a lot of energy from the oxygen, which speeds their growth, and a large portion of the organic waste is converted to new cells. These new cells are not stabilized but simply change form, and this new biological sludge presents a significant disposal problem. In the case of anaerobic treatment due to the lack of oxygen, the microorganisms gain little energy and the growth 
rate is slow. Only a small portion of the organic matter is converted to new cells while the major portion of the degradable waste is converted to biogas (McCarty, 1964). This reduces the cost of sludge handling, waste stabilization, and disposal costs. (c) Anaerobic digestion produces biogas which has significant energy value, which can be used as fuel to power the digester or to generate electricity for other purposes.

There are a few disadvantages associated with anaerobic digestion. The major disadvantage is that this process requires relatively high temperatures. Temperatures in the range of $85^{\circ} \mathrm{F}$ to $95^{\circ} \mathrm{F}$ are required for for optimum digester performance. Another disadvantage is the slow growth rate of the methane producing bacteria, which results in longer periods of time for the startup process and the rate at which the process can adjust to change in digester feed, temperatures, and other environmental conditions (McCarty, 1964).

\section{Operating Parameters for $\mathrm{AD}$}

The rate at which the anaerobic bacteria grow is the most important aspect when it comes to the efficiency of the anaerobic digester. The operating parameters must be controlled to obtain optimum anaerobic bacteria activity for maximum efficiency of the digester. If any one of the operating parameters varies from the specified conditions, it can lead to the inactivity of the bacteria and, hence, stall the AD process. Key operating parameters are listed below. 


\section{$3.1 \mathrm{pH}$}

A stable $\mathrm{pH}$ indicates system equilibrium and digester stability. $\mathrm{pH}$ in the system may vary with different biological conversions taking place in the digester. The optimum $\mathrm{pH}$ range for methanogenic bacteria is between 6 and 8 , but the optimum $\mathrm{pH}$ for a group as a whole is near 7 (Zaher, 2007). Most studies indicate that the $\mathrm{pH}$ required for good AD performance is 6.5 to 7.5 . During the acidification stage, the acetogenic bacteria produce organic acid. A high loading of volatile solids (VS) can result in the production of a high amount of organic acid which can in turn lower the overall $\mathrm{pH}$ below 5 , a level that is lethal to the methanogenic bacteria. On the other hand, if the methanogenesis is occurring at a high rate, it can lead to a high production of ammonia which can increase

the overall $\mathrm{pH}$ above 8 . High $\mathrm{pH}$ can impede acetogensis and acid formation and can kill the methanogenic bacteria (Rapport,2008).

\section{2 $\underline{\text { Temperature }}$}

Optimum AD occurs mainly in two temperature ranges - the mesophilic and thermophilic ranges. The mesophilic range is between $20^{\circ} \mathrm{C}$ to $40^{\circ} \mathrm{C}$ with $35^{\circ} \mathrm{C}$ being considered to be the optimal temperature. Bacteria operating in the mesophilic range is more robust and can tolerate changes in environmental parameters, especially temperature. Thermophilic temperature range is between $50^{\circ} \mathrm{C}$ to $70^{\circ} \mathrm{C}$ (Young and Cowan, 2004). Thermophilic range allows a higher organic loading rate and has a lower retention time. The disadvantages are that the bacteria operating in this temperature range 
is sensitive to slight environment changes. Also, a high amount of energy is required for heating to keep the system in the thermophilic range.

\subsection{Carbon/Nitrogen Ratio}

The relationship between the amount of carbon and nitrogen present in feed stock is represented by the carbon/nitrogen $(\mathrm{C} / \mathrm{N})$ ratio. A high $\mathrm{C} / \mathrm{N}$ ratio is an indication of rapid consumption of nitrogen by methanogens and results in lower gas production. On the other hand, a lower $\mathrm{C} / \mathrm{N}$ ratio causes ammonia accumulation and $\mathrm{pH}$ values exceeding 8.5, which can impede acetogenesis. A C/N ratio of 20/1-30/1 is the optimum range for

$\mathrm{AD}$, based on the biodegradable organic carbon. To maintain the $\mathrm{C} / \mathrm{N}$ level of the digester material at acceptable levels, materials with high $\mathrm{C} / \mathrm{N}$ ratio can be mixed with those with a low $\mathrm{C} / \mathrm{N}$ ratio, i.e. organic solid waste can be mixed with municipal sewage, biosolids, or animal manure (Verma, 2002).

\subsection{Organic Loading Rate}

The organic loading rate (OLR) is the amount of organics that can be handled by the $\mathrm{AD}$ system at a particular time. A high OLR rate can lead to the crashing of the $\mathrm{AD}$, because the acetogenic bacteria grow at a faster rate and produce acids at a rapid rate. The methanogenic bacteria grow at a slower rate and are not able to convert the high amount of acids. This leads to accumulation of the acids which will raise the overall $\mathrm{pH}$ of the system and kill the methanogenic bacteria which will halt the AD process (Verma, 2002). Maintaining a consistent ratio of volatile acids to alkalinity ensures that conditions are right for proper anaerobic digestion operation. A va/alk ratio in a well operated 
anaerobic digester, ranges between 0.1 and 0.3 (Qasim, 1998). Low biogas production and a low $\mathrm{pH}$ are indicators of a high OLR.

\subsection{Toxicity}

Toxicants are components in the wastewater that can cause a negative effect on the bacterial activity. Low concentrations of minerals (sodium, potassium, calcium, magnesium, ammonium, and sulfur) stimulate the bacterial growth, but become inhibitory as their concentrations increase. Heavy metals such as copper, nickel, chromium, zinc, and lead are essential for bacterial growth in small quantities, but higher quantities have a toxic effect (Zaher, 2007). The toxic components in the wastewater need to be reduced to a concentration below the toxic threshold value for optimum AD.

\subsection{Mixing}

The flow of wastewater through the digester impacts the degree of contact of the waste water with the bacteria which affects the digestion process. Mixing helps with the uniform distribution of bacteria throughout the mixture resulting in improved digestion of the wastewater. Mixing also prevents scum formation and avoids temperature gradients within the digester (Verma, 2002). It also helps in particle size reduction as digestion progresses and aids the escape of gas from the mixture. Excessive mixing can disrupt the microbes; so, slow mixing is preferred. The kind of mixing equipment and amount of mixing varies with the type of reactor and the solids content in the digester. 


\subsection{Retention time}

The Hydraulic retention time (HRT) is the average time it takes for the organic material in the wastewater to digest. The HRT for most dry (high solids) anaerobic processes ranges between 14 and 30 days while for wet (low solids) anaerobic processes it can be as low as 3 days (Zaher, 2007). The required retention time for completion of the AD reactions varies with differing technologies, process temperature, and waste composition.

\section{General Process Description}

Anaerobic digestion at a municipal waste water treatment plant is divided into four stages: Pretreatment, waste digestion, gas recovery, and residue treatment (Verma, 2002). Waste is pretreated in digestion systems to obtain homogenous biomass. This involves the mechanical sorting of non-digestible materials like glass, metals, stones etc. some of which can also be recycled.

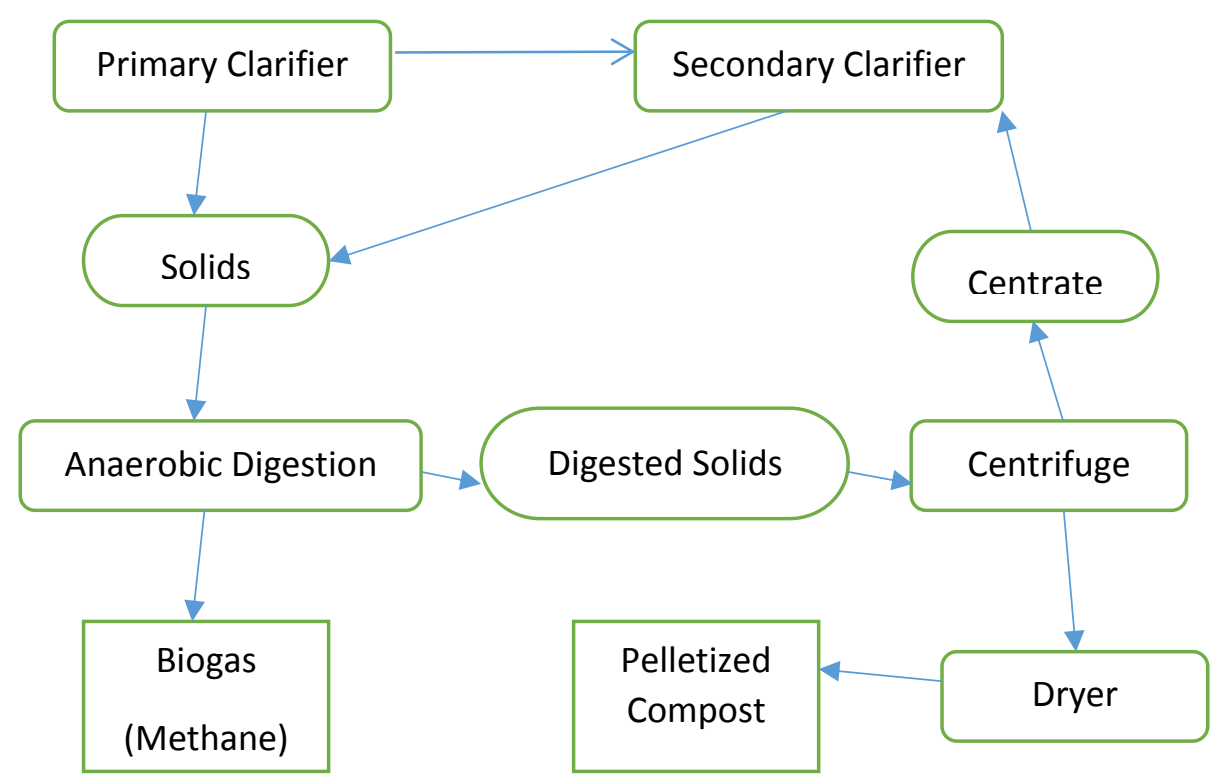

FIGURE 2 - Basic schematic of Waste Water Treatment Plant 
The municipal waste then goes through the primary and secondary clarifiers where the settled sludge is removed. Polymer is added to the sludge before it enters the digester. The sludge is then fed to the digester where it is sometimes diluted to achieve the desired solids content and it remains in the digester for a designated retention time. The solids in the sludge are reduced to methane gas in the anaerobic digester. The digested solids are then dewatered in the centrifuge. Polymer is added in this process for better separation of water from then solids. The centrate from the centrifuge is then recycled in the waste water plant. The solids from the centrifuge are then sent to the drier where it is dried and pelletized and sold as a compost product.

\section{B. EFFECT OF POLYMER ON ANAEROBIC DIGESTION}

Water-soluble, cationic polymers are used extensively in waste water treatment plants worldwide. The primary purpose of the addition of the polymers is to improve the overall efficiency of the thickening and dewatering of sludge at the wastewater treatment plant. The most commonly used polymers are polyacrylamide based cationic polymers. The advantage of using cationic polyelectrolytes is that they neutralize the negatively charge suspended solids in wastewater.

Sludge conditioning is a treatment process used in a wastewater facility and is intended to increase the efficiency of sludge thickening and dewatering process. The most common way of achieving this is by adding chemical coagulants. This works by coagulating sludge solids into flocs and thereby improving the settling characteristics of 
the solids by releasing water which was strongly associated with the solids (Raudenbush, 1994). Sludge solids concentrations which begin at 1 to 10 percent can be increased to 20 to 35 percent after chemical conditioning (Water Pollution Federation, 1988).

Sludge dewatering is a physical process that is used to reduce the liquid content of sludge to where it becomes a solid. There are many advantages to this such as the dewatered sludge is easier to handle, costs less to transport, has a higher energy value, is a better material for composting, has decreased odor, and produces less leachate when placed in a landfill (Metcalf and Eddy, 1991). The dewatering process produces a solid sludge 'cake' which can be ultimately disposed of, and a liquid stream that gets recycled back to the upstream of the wastewater treatment process.

Chemical conditioners can be inorganic, such as alum, lime, and ferric chloride or organic such as polymers. Organic polymers cost more than inorganic coagulants on a unit basis but they are preferred as they are more efficient in sludge dewatering because the coagulants themselves do not add significantly to the overall sludge volume, and they operate at a wide range of $\mathrm{pH}$ levels (Water Pollution Control Federation, 1988). Organic polymers are also safer to handle and easier to work with.

The amount of polymer added to the sludge must be carefully monitored to make sure the chemical conditioning is as efficient as possible. Under-dosing of polymer results in low total solids concentrations in the dewatered cake. Overdosing of polymer results in poor dewaterability, unnecessary expense, and the possibility of significant 
residual polymer concentrations recycled through the water treatment system (Raudenbush, 1994)).

As should be the case when any synthetic chemical is eventually released to the environment, the use of polymeric flocculants in wastewater plants leads to questions about their possible environmental effects. In a waste water treatment plant, coagulant polymer is added to sludge prior to dewatering. After adding the coagulant polymers to the sludge the polymer resides in both the solid and aqueous phase. It is essential to determine how much polymer goes along with the solid phase and how much goes along with the aqueous phase. It was found that most of the polymer remains with the wastewater solids and leaves the waste water treatment plant with the biosolids (Dentel, 2000). Bio-solids resulting from dewatering process where polymers are added, ultimately are landfilled, incinerated, land applied, or composted along with other biosolids.

It has also been observed that polymers are overdosed due to the ever-changing sludge characteristics and the desire to prevent process upsets. Incomplete adsorption of the polymer onto the sludge, and overdosing, can result in residual polymer in the liquid stream of the dewatering process (Soponkanaporn and Gehr, 1987). This liquid return stream which is recycled to the beginning of the treatment plant, is comprised of water which is removed from the sludge during centrifugation. The residual polymer is then recirculated through the entire waste water treatment process. 
Cationic polyelectrolytes have a high affinity for negatively charged particles. The recycled wastewater which contains the residual polymer could absorb the raw wastewater solids and settle out in the primary clarifier. The residual polymer can also enter the aeration basin and the secondary clarifiers (Raudenbush, 1994). The polymer that settles along with the wastewater solids from the clarifiers would go to the anaerobic digestion process. The solids that contain the polymer may affect the performance of the anaerobic digestion process.

As mentioned earlier among the different types of flocculants, polyacrylamides (PAM) have become the primary choice to enhance dewatering through charge neutralization and interparticle bridging (Hoadley, 2011). Polyacrylamides are xenobiotic polymers whose monomeric unit is acrylamide. The backbone consists of repeating main $\left[-\mathrm{CH}_{2}-\right]$ units, with alternate carbon atoms bound to the side groups of either amide or carboxyl. Cationic polyacrylamide derivatives are produced by reacting polyacrylamide with other chemicals to add the functional groups to the polyacrylamide molecule. The molecular weights of these polymers are in the millions and they also have high charge densities. They become cationic when dissolved in wastewater by dissociation of the anion associated with the quaternary amine (Raudenbush, 1994).

Anaerobic degradation of polyacrylamide polymers has been studied by researchers, but the results seem contradictory. Assessment of biodegradability of polymer is difficult due to various factors. It is not possible to know the exact structure of the polymer coagulant used in wastewater treatment as the formulations of these polyelectrolytes is proprietary, which makes it difficult to do certain types of analysis ( 
Dentel, 2000). In order to properly determine the fate of the polymer throughout its course in the waste water treatment facility, it is necessary to be able to detect the substance. Concentrations of polymers are extremely hard to measure both in the solid and liquid phase. Polymer in wastewater is hard to detect using traditional analytical methods. Indirect measurements and analysis are usually used to determine the polymer concentration.

Theoretically, polymers can serve as a food source for some organisms. However, polymer does not compete with other biodegradable material when it comes to anaerobic digestion. It has been shown that polymers have limited biodegradability in anaerobic environments. Portions of the polymer structure have degraded but the backbone chain appeared to remain intact and remain in the system.

Polymer found in the wastewater can affect anaerobic digestion in several negative ways. The residual polymer can be toxic to the bacteria that promote anaerobic degradation. The polymer can end up binding with the substrate which can limit the anaerobic bacteria's access to energy and nutrients, thus decreasing the overall efficiency of anaerobic digestion (Dentel,2000). Also, if the polymer partially degrades, the byproducts could have negative effects on the digestion process.

One of the earliest studies that investigated polymer interactions with anaerobic microbial process was performed by Schumann and Kunst (1991). They used cationic and anionic ${ }^{14} \mathrm{C}$-labeled polyacrylamides in 500-mL batch digestions, and based on the location of the marked carbon, concluded that neither polymer has degraded to a 
significant extent. The experimental results showed that cationic polymer was still primarily in the solid phase which was $88.5 \%$ and the only $2.5 \%$ of the ${ }^{14} \mathrm{C}$ was in the gaseous phase. The overall COD destruction of the synthetic feed substrate exceeded $95 \%$. This suggests that the polymer is not toxic to the microbial population. The true extent of the degradation was unknown as this type of polymer labeling restricted degradation information to the main $\left[-\mathrm{CH}_{2}-\right]$ chain and the adjacent carbon atoms.

Grula, Huang and Sewell (1994) tested the notion that polyacrylamides can somehow stimulate the growth of microorganisms. The objective of the study was to determine if polyacrylamides can stimulate microbial growth, how the stimulation occurs, and if it is accompanied by the degradation of the polymer molecule. The second phase of the study was to investigate the impact of polyacrylamide polymers on sulfate-reducing bacteria. These organisms are highly anaerobic and hydrogen sulfide is a metabolic product which is generally very toxic. When the polymer breaks down it gets hydrolyzed to polyacrylic acid which does not provide any type of stimulation for the bacteria. Polyacrylic acid is somewhat toxic, this is possibly due to the binding of the essential divalent cations. The study indicated that one of the roles of polyacrylamide polymer may be to serve as a source of nitrogen for sulfate reducing bacteria. However, it was noted that the cationic polyacrylamide polymer strongly inhibited microbial growth.

The microbial growth rate was measured based on viscosity changes in the polymer. The growth rate was calculated by the increase in the optical density of the microbial suspension and the degree of polymer degradation from viscometric changes. The degree of microbial growth was determined by measuring the absorbance at $540 \mathrm{~nm}$. 
There are two types of viscosity measurements: Brookfield viscosity and screen factor. A Brookfield viscometer measures the true or absolute viscosity of the solution. Screen factor is the measurement of the viscoelastic flow properties of the polymer solution. The screen factor of a solution is defined as the flow time of the polymer solution divided by the flow time of the same volume of water at the same temperature (Grula,1994). Screen factor is more sensitive to changes in polymer quality. From the viscometric results, it was very clear that significant reductions occurred in the screen factor of the polymer under strict anaerobic conditions.

The study also stated that it was very unlikely that the polyacrylamide can serve as a cellular carbon. The polymer was labeled in the carboxyl carbon with ${ }^{14} \mathrm{C}$. After 4 days of incubation under anaerobic conditions it was seen that less than $0.05 \%$ of the total recovered radioactivity was cell associated. The very long chains of [- $\left.\mathrm{CH}_{2}-\right]$ units in the polyacrylamide is not amenable to enzymatic breakdown. Saturated hydrocarbon monomers with chains of 45 carbon atoms or more are extremely resistant to microbial attack (Amexander, 1965).

Chang, Raudenbush and Dentel (2001) investigated the overall effect and fate of flocculant polymers. The study was done to determine the anaerobic biodegradability of a typical flocculant polymer. To simulate an anaerobic environment, a batch bioassay technique also known as the serum bottle test was performed. The inoculum used from an anaerobic digester and the temperature in the bottles were maintained at $35^{\circ} \mathrm{C}$. The gas production was measured over time. The polymer used for the experiment was Percol 787 which is a commonly used polymer. Percol 787 is a cationic derivative of 
polyacrylamide. During the experiment subsamples were withdrawn for COD and other analyses.

The gas production in the serum bottle with Percol 787 as substrate was significantly higher when compared to the serum bottle with just the inoculum. The concentration of Percol 787 in the bottle was $1100 \mathrm{mg} / \mathrm{L}$ which is significantly higher when comparing to the trace amounts of residue polymer found in wastewater. Gas production from the anaerobic digestion of wastewater containing residual polymer between $0.1 \mathrm{mg} / \mathrm{L}$ to $10 \mathrm{mg} / \mathrm{L}$ could be considered negligible. The results from this experiment shows that the polymer is partially degraded under anaerobic conditions. It appears that the cationic pendant group is removed by ester hydrolysis leaving an acrylamide or acrylate monomer within the main polymer chain (Chang, 2001). It seems that the portion that is removed has been completely degraded anaerobically. The partial degradation shown in the experiment is consistent with previous studies that suggest only partial degradation of polymer is possible.

Chu, Lee, Chang, You, Liao and Tay (2003) examined the effects of three polyelectrolyte flocculants (cationic, non-ionic and anionic) on anaerobic digestion of wastewater sludge. Methane production, floc characteristics, and other process parameters were monitored along with the digestion tests. The digestion rates for the nonionic and anionic polymer were similar to those for sludge without polymer. The cationic polymer dosed sludge had an increased methane production rate for the first six days when compared to the sludge without polymer. In the following stage the sludge with the cationic polymer had a decreased digestion rate. 
The observation made here was that the polymer did not have a toxic effect on the inoculum. Microphotographic observation revealed that the flocs of the sludge conditioned with the cationic polymer were not only of large size, but also resistant to structural deterioration during anaerobic digestion. The lower digestion of the sludge conditioned with the cationic polymer may be attributed to the much larger floc size which in turn resists efficient mass exchange with sludge flocs.

Yang, had studied the effect of trace amounts of polyacrylamide on long term performance of activated sludge. The effluent from the treated activated sludge contains trace amounts of polyacrylamide. The objective of the research was to understand the effect of trace amounts of polyacrylamide on sludge performance. Four lab scale sequencing batch reactors, each with a working volume of $3 \mathrm{~L}$ were investigated with different concentrations of polyacrylamide. It was observed that polyacrylamide concentrations above $1 \mathrm{mg} / \mathrm{L}$ it led to the formation of large amounts of loose structure flocs which caused sludge disintegration. The study also stated that when the concentration of polyacrylamide was above $1 \mathrm{mg} / \mathrm{L}$ it had negative effects on the removal of COD. This was attributed to the bad settleability and lower microbial activity which was ascribed to both of completion during bridging between polyacrylamide polymers and huge electronic exclusion. 


\section{DETECTION AND QUANTIFICATION OF RESIDUAL POLYACRYLAMIDE POLYMER IN WASTEWATER}

Different types of analysis techniques have been reported in literature for the detection and quantification of polymers. The ideal quantification technique should be based on the unique aspects of coagulant polymer chemistry, as this would decrease the probability of interference from other particles. Some of these techniques are suitable for extraction, separation, identification, and quantification of polymers in water-based environmental and industrial samples, but the accuracy and reproducibility of these methods heavily depend on the polymer and sample characteristics (Gibbons, Omerci, 2013).

Among the different types of polymers that are used for sludge thickening and conditioning, polyacrylamides (PAM) are the most common synthetic polymer used in wastewater facilities. Polyacrylamides are xenobiotic polymers whose monomeric unit is acrylamide. The backbone consists of repeating main $\left[-\mathrm{CH}_{2}-\right]$ units, with alternate carbon atoms bound to the side groups of either amide or carboxyl (Dentel,2000). Cationic polyacrylamide derivatives are produced by reacting polyacrylamide with other chemicals to add the functional groups to the polyacrylamide molecule.

Literature research has shown various analytical methods that have been used for the quantification of PAM concentration in various aqueous solutions. The different analysis techniques for PAM can be classified into four categories: 
1. Methods that are based on chemical properties of amide in polyacrylamide which includes fluorescence spectrometry, amide hydrolysis which detects ammonia, and the N-bromination method ( $\mathrm{Lu}$ and $\mathrm{Wu} 2003$ ).

2. Methods that are based on the physical properties of the large molecular size of polyacrylamide which includes viscosity measurement, flocculation-based method, and size exclusion chromatography (SEC) (Lu and Wu 2003).

3. Methods that are based on the chemical properties of the amide groups and the physical properties of the large molecular size of polyacrylamide which includes colloid titration, turbidimetric method, and polarography.

4. There are also other special methods for quantification of polyacrylamides which includes total organic carbon measurement and radioactive labeling.

Methods based on chemical properties amide groups alone have relatively low detection limits and are beneficial when it comes to detecting polymer in wastewater. Fluorescence spectrophotometry can detect polyacrylamide concentration as low as $20 \mu \mathrm{g}$ $\mathrm{L}^{-1}(0.02 \mathrm{ppm})$ (Hendrickson and Neuman, 1984). Another advantage is the sensitivity of this method doesn't change with the molecular weight of the polyacrylamide if the ratio between the amide group and the carboxylic group in the polyacrylamide does not change (Lu and $\mathrm{Wu}, 2003$ ). However, with the increasing degree of polyacrylamide hydrolysis, the ratio of amide groups to carboxylic groups becomes lower in the polyacrylamide. Also, since we are dealing with wastewater containing a lot of unknown substances, the amide group or nitrogen containing species has an interference effect on the analysis. 
The second set of methods, based on the physical property of the polyacrylamide, has much simpler procedures compared to chemical methods and is less labor intensive (Aghamir-Baha, 2014). It is hard to get consistent results for viscosity measurement and flocculation-based method as they are vulnerable to the effect of salt and temperature conditions. This is because the configuration and the gyration radius of polyacrylamide molecules are greatly affected by salt concentration and temperature of the solution as indicated by light scattering measurements (Muller, 1979). The size exclusion chromatography method detects polyacrylamide after separating it from interferential impurities. This is not feasible when we are dealing with wastewater.

Methods based on both chemical and physical properties of polyacrylamides are advantageous as they have a higher selectivity of the polyacrylamide when compared to other methods. However, these methods are also complicated and often not practical as they are more vulnerable to interference from salts, organic matters, temperature and $\mathrm{pH}$ conditions.

Total organic carbon is a non-selective method which does not exclusively quantify polyacrylamide, and radioactive labeling is only effective if the polyacrylamide is tagged with a radioactive isotope making this method very complicated and labor intensive.

In summary, previous studies have shown that analytical methods that are available for the detection and quantification of polymers are complex and require advanced research instrumentation, trained personnel, and pretreatment and processing of samples that may take several days. The simpler analytical methods such as those that 
rely on colorimetric methods, titration, turbidity, and viscosity, lack specificity and sensitivity particularly at low polymer concentrations (Aghamir-Baha, 2014). Therefore, neither the advanced nor the simpler techniques used for polymer detection and quantification are suitable for real-time applications in the field or for process optimization.

A simple and sensitive method for the detection and quantification of polymer in wastewater treatment process is lacking. Budd et al (1995) developed a new method to directly measure residual polymer for industrial applications where polymer is used for water solid separation. Fluorescence emission spectroscopy was used to determine the concentration of residual polymer in the filtrate. Fluorescence emission spectroscopy is extremely rapid and sensitive but the species being monitored must be fluorescent. A typical cationic polyelectrolyte is not fluorescent nor is it sufficiently fluorescent for monitoring by fluorescence emission spectroscopy. The mechanism of a cationic polyelectrolyte and a fluorescent chemical or tracer are different. Due to this the fraction of the polymer consumed cannot be determined by correlating it to the concentration of the tracer consumed.

For the method Budd proposed, depending on the concentration of polymer being added to the untreated water, a fluorescent chemical which has an opposite charge to the polymer is added. The polymer and the fluorescent chemical combine to produce a complex based on their opposing charges. This complex can be monitored to find the polymer concentration in the effluent (centrate) by using fluorescence emission spectroscopy. This method was the first attempt to directly measure the residual polymer 
concentration. The challenges faced by this method was the need for introduction of an external fluorescent molecule and the potential interaction of the fluorescent molecule with other molecules in the wastewater.

The potential of $\mathrm{U}-\mathrm{V}$ Vis for the detection and measurement of residual polyacrylamide polymer was investigated by Aghamir-Baha (2014). The objective of this study was to determine optimum polymer addition to digested sludge for dewatering purposes based on the residual polymer in the centrate. The absorbance method (UVVis) was performed on digested sludge conditioned with three different polymer stock solutions. The first polymer was Zetag8160 which is a polyacrylamide, has medium-high cationic charge, has high molecular weight, and is in a granular solid form. The second polymer was SNF475 which is a polyacrylamide, has a high charge density, has ultrahigh molecular weight, and is in a granular solid form. The third polymer was CIBA which is a polyacrylamide, has a high charge density, has high molecular weight, and is a free flowing microbead.

The performance of dewatering of sludge also changes by variations in factors such as the duration and the intensity of the mixing of the polymer and the sludge. By keeping the intensity and the duration of the mixing the same, the only variable to the dewatering performance would be the polymer concentration and the type of polymer used. Five different concentrations of each polymer were tested. After mixing, the filtrate from the different sludge and polymer combinations were collected. The filtrate was then diluted at a ratio of 1:9, one part of the filtrate was mixed with nine parts of deionized water. The absorbance of the diluted samples was measured using a UV-Vis 
Spectrophotometer. The absorbance spectra for the three different polymers (Zetag8160, SNF475 and CIBA) was measured over a wavelength of 190-800 nm. For all three polymers, the peak of the polymer concentration occurred at wavelength of $190 \mathrm{~nm}$.

It was discussed in the article that at the absorbance wavelength of $190 \mathrm{~nm}$, as the polymer dose increased, the flocs got bigger and stronger which led to the smaller particles getting caught up in the large flocs. As the smaller particles were incorporated into the large flocs, they were removed from the wastewater and, as a result, the filtrate became clearer which resulted in a decrease in the absorbance of the filtrate (AghamirBaha, 2014).

One thing to note here is the difference in the absorbance values for all three polymers for the same concentrations. As previously discussed the optimum conditioning by the polymer on the sludge is different for different polymers. The peak of absorbance for all three polymer samples was at $190 \mathrm{~nm}$ (Aghamir-Baha, 2014). From these results, it has been shown that residual polymer can be measured in the filtrate by using the UVVis method. 


\section{EXPERIMENTAL}

\section{A. EXPERIMENTAL PLAN}

The aim of the thesis was to find the impact of coagulant residue polymer in wastewater on anaerobic digestion. Wastewater dosed with polyacrylamide polymer of different concentrations were anaerobically digested in $500 \mathrm{ml}$ bottle reactors. Concentration of residual polymer found in wastewater can be up to $10 \mathrm{mg} / \mathrm{L}$ (Yang,2011). For this reason, the concentration of polymer added to the bottle reactors ranged from $1 \mathrm{mg} / \mathrm{L}$ to $10 \mathrm{mg} / \mathrm{L}$. Seven bottle reactors were setup in the respirometer with seven different conditions to analyze the impact of polymer in wastewater on biogas production. The seven different conditions have been listed below in TABLE I.

\section{TABLE I}

DIFFERENT BOTTLE REACTOR CONDITIONS FOR ANAEROBIC DIGESTION RESPIROMETER EXPERIMENT

\begin{tabular}{|c|l|l|l|}
\hline $\begin{array}{c}\text { Bottle } \\
\text { Reactor }\end{array}$ & \multicolumn{1}{|c|}{ Substrate } & Innoculum & \multicolumn{1}{|c|}{ Polymer } \\
\hline 1 & Wastewater $-400 \mathrm{ml}$ & MSD sludge $-100 \mathrm{ml}$ & PAM $-1 \mathrm{mg} / \mathrm{L}$ \\
\hline 2 & Wastewater $-400 \mathrm{ml}$ & MSD sludge $-100 \mathrm{ml}$ & PAM $-2.5 \mathrm{mg} / \mathrm{L}$ \\
\hline 3 & Wastewater $-400 \mathrm{ml}$ & MSD sludge $-100 \mathrm{ml}$ & PAM $-5 \mathrm{mg} / \mathrm{L}$ \\
\hline 4 & Wastewater $-400 \mathrm{ml}$ & MSD sludge $-100 \mathrm{ml}$ & PAM $-7.5 \mathrm{mg} / \mathrm{L}$ \\
\hline 5 & Wastewater $-400 \mathrm{ml}$ & MSD sludge $-100 \mathrm{ml}$ & PAM $-10 \mathrm{mg} / \mathrm{L}$ \\
\hline 6 & Wastewater $-400 \mathrm{ml}$ & MSD sludge $-100 \mathrm{ml}$ & PAM - None \\
\hline 7 & DI water $-400 \mathrm{ml}$ & MSD sludge $-100 \mathrm{ml}$ & PAM - None \\
\hline
\end{tabular}

All reactions were run simultaneously for 120 hours in the respirometer. The volume of biogas produced in the bottle reactors was measured using a respirometer. The 
difference in biogas production volumes assisted in analyzing the impact of polymer in wastewater on anaerobic digestion.

The Chemical Oxygen Demand (COD) in the wastewater is directly proportional to the amount of biogas produced by the wastewater. COD values of the wastewater before and after digestion were measured using a spectrophotometer. The decrease in COD values in the different polymer dosed wastewater samples was analyzed to see the impact of polymer on anaerobic digestion.

The theoretical biogas production was then calculated from initial COD values and compared to the actual biogas values recorded by the respirometer. This was another analysis method to see the impact of polymer on anaerobic wastewater digestion.

Biogas was analyzed to determine its methane content using a thermal conductivity detector (TCD) in the Gas Chromatograph (GC). The TCD detector sensed the change in the thermal conductivity of the biogas constituents, in this case mainly methane and carbon dioxide, and compared it to the reference flow of a carrier gas (hydrogen). It also helped in analyzing whether polymer in the wastewater impacted the methane quality in the biogas.

The UV-Vis absorbance method was used to detect the different concentrations of polymer in wastewater. The UV-Vis measurement was used as an indirect method for detecting the polymer in the wastewater. Based on the amount of polymer in the wastewater the solids separate out. In UV-Vis, a beam with wavelength varying between 200 and $800 \mathrm{~nm}$ passed through the wastewater dosed with polymer in a cuvette. The 
absorbance spectrum chosen for this study was over the wavelength of 320 to $670 \mathrm{~nm}$. This range was chosen because this is where the absorbance values showed the biggest change for the different wastewater samples. The UV-Vis spectroscopy was used to measure the absorbance of the wastewaters dosed with different amounts of polymer. The absorbance spectra of the polymer dosed wastewater were recorded before and after anaerobic digestion. This allowed us to see if there was an impact on the polymer in the wastewater by anaerobic digestion.

When the polymer breaks down it undergoes hydrolysis and ammonia is released from the amide. To validate this, the concentration of ammonia was detected from the wastewater samples before and after digestion. The ammonia was measured by colorimetry using a spectrophotometer.

\section{B. MATERIALS}

\section{Substrate (Wastewater)}

The wastewater was obtained from the stream that goes into the centrifuge for the removal of solids at the MSD plant. This stream was a mixture of the digested sludge and the solids from the secondary treatment containing 3\% solids. The stream was then centrifuged at the lab and the supernatant was collected after the centrifugation. The supernatant was then added to the bottle reactor for the respirometer experiment. 


\section{Inoculum (MSD Sludge)}

The inoculum used for this experiment was collected from the MSD anaerobic reactors. The sludge was already activated when it was brought into the lab and it was used immediately for the respirometer experiment. From previous respirometer experimental results obtained at the lab the substrate to inoculum ratio was determined to be at a 4:1 ratio for optimum biogas production.

\section{Polymer (Polyacrylamide)}

Polyacrylamide (PAM) of different concentrations were added to the substrate. The polymer chosen for this experiment was the same as the one that was used at the MSD plant which is Clarifloc CE-1063. This is a high charge cationic polyacrylamide in emulsion form.

\section{EQUIPMENT}

The wastewater samples dosed with polymer were characterized before and after digestion for the concentration of COD and ammonia. The supernatant obtained after centrifugation from the different bottle reactors was measured for COD and ammonia values. The concentration of COD and ammonia were measured by colorimetry using a spectrophotometer (Hach, model \# DR 3900) and tests vials pre-loaded with analytic reagents (Hach TNT vials:822, 830). Total solids (TS), total dissolved solids (TDS) and total suspended solids (TSS) were measured using standard methods from United States Geological Survey (USGS, 1989). 
Biogas was analyzed to determine methane and carbon dioxide concentrations.

The gas analysis was performed using an SRI 8610C Gas Chromatograph (FIGURE 3) (SRI Instruments Inc., Las Vegas NV) with a Haysep D column (Restek Corporation) and thermal conductivity detector (TCD) for methane and carbon dioxide detection.

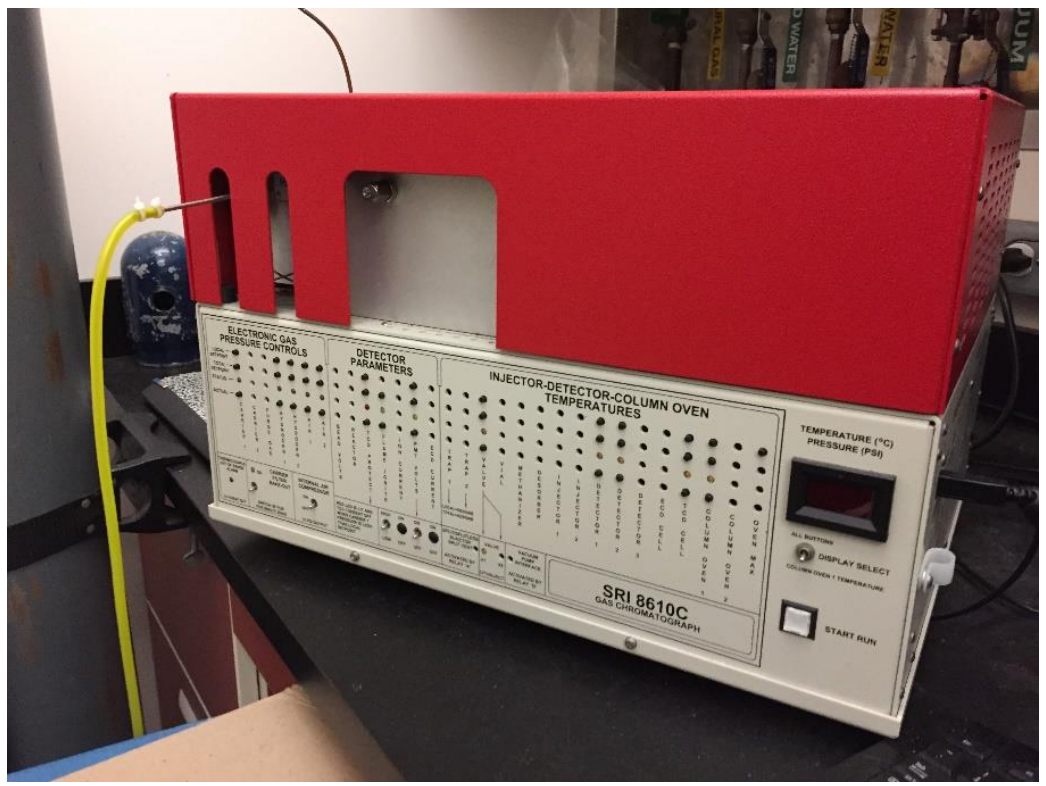

FIGURE 3 - Gas Chromatograph used for Biogas Analysis (SRI 8610C)

Anaerobic digestion tests were performed with a system of batch pulse-flow respirometers (FIGURE 4) (Respirometer Systems \& Applications LLC, Fayettville, AZ, USA, model \# RSA, PF-8000). The respirometer continuously monitored biogas production in real time. The biogas that was produced flows into an internal storage chamber and was released when a pre-set pressure buildup was detected by a pressure transducer. These incremental volumes were carefully controlled through accurate calibrations established by RSA (Respirometer Systems \& Applications LLC). The 
pressure transducer was connected to a computer which has a data acquisition software (developed by Respirometer Systems \& Applications LLC) to record and monitor gas production data.

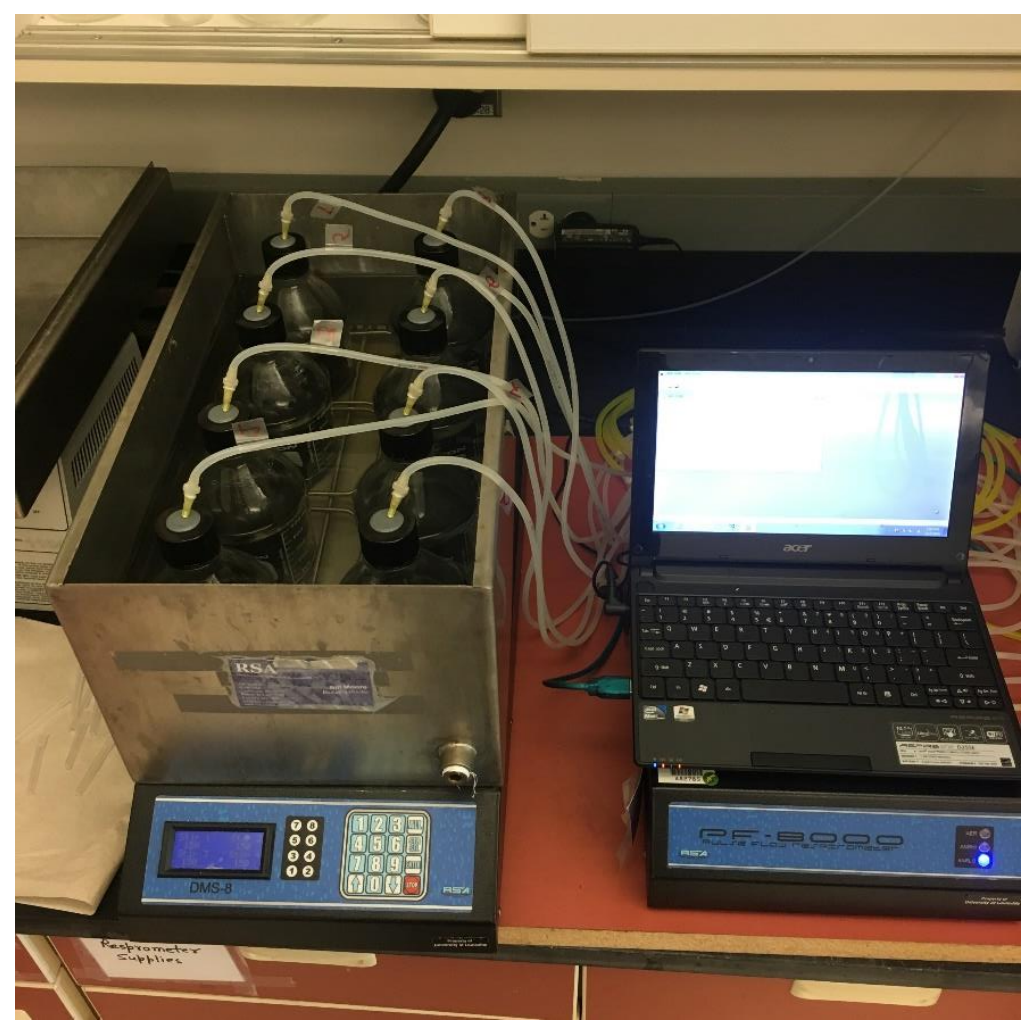

FIGURE 4 - Lab scale respirometer for anaerobic digestion (PF-8000 model)

For the detection of polymers in wastewater, the UV-Vis absorbance method was used. The UV-Vis method indirectly measured the polymer in the wastewater. Based on the amount of polymer in the wastewater the solids separate out. The UV-Vis spectrometer (FIGURE 5) (Lambda 950, Perkin Elmer) was then used to measure the absorbance of the wastewaters dosed with different amounts of polymer. The absorbance spectra of the polymer dosed wastewater were recorded before and after anaerobic 
digestion. This determined whether the polymer in the wastewater had an impact on anaerobic digestion.

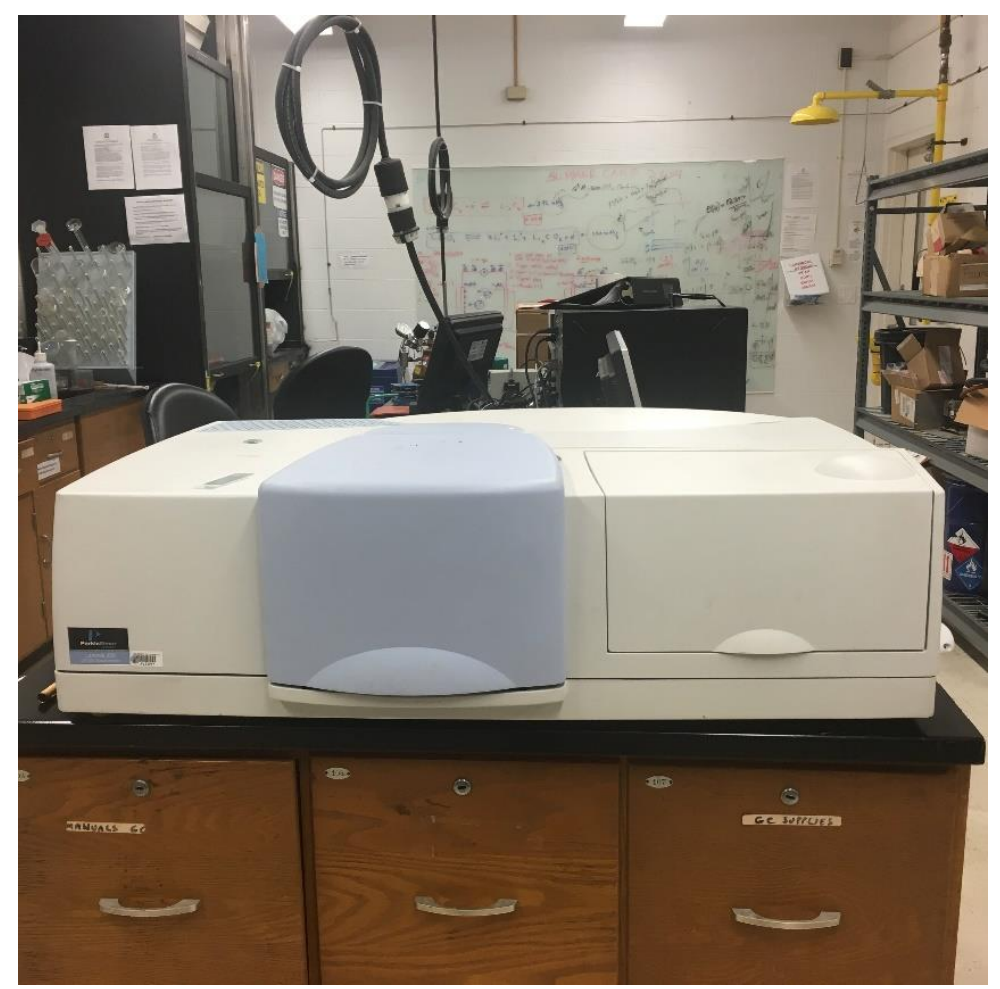

FIGURE 5 - UV Vis Spectrometer used for polymer detection (Lambda 950 model)

\section{EXPERIMENTAL PROCEDURE}

1. Procedure for preparation of reactants for anaerobic digestion in bottle reactor

The first step was the preparation of the polymer. Polymer (Clarifloc CE-1063), obtained in an emulsion form, was mixed with water to form a one percent solution; onepart polymer was mixed with 99 parts water. 
Wastewater that was collected from the MSD plant contains 3 percent solids. This was centrifuged and the supernatant was collected for the anaerobic digestion test. The polymer solution that was prepared earlier was mixed with the wastewater to prepare each wastewater sample dosed with polymer. Five different concentrations of polymer were added to the wastewater $(1 \mathrm{mg} / \mathrm{L}, 2.5 \mathrm{mg} / \mathrm{L}, 5 \mathrm{mg} / \mathrm{L} .7 .5 \mathrm{mg} / \mathrm{L}$ and $10 \mathrm{mg} / \mathrm{L})$.

The next step was to add the polymer dosed wastewater and the biomass that contained the anaerobic bacteria to the $500 \mathrm{ml}$ serum bottles. $400 \mathrm{ml}$ of the substrate (polymer dosed wastewater) and $100 \mathrm{ml}$ of the biomass (MSD sludge) was then added to the serum bottles.

\section{Procedure for respirometer experiment setup}

The bottles were then sealed using the rubber septa caps. All the serum bottles were then flushed with nitrogen gas to create an anaerobic environment inside the serum bottle. All the bottle reactors were placed in a water bath at a controlled temperature of $35{ }^{\circ} \mathrm{C}$ so the reaction would occur in the mesophilic range. The reactor bottles were connected to the pressure transducers with needles and tygon tubes. Stirring was maintained at $150 \mathrm{rpm}$ with magnetic stirrers. The biomass used for this experiment was obtained within the week from the MSD plant, so there was no need to stabilize the sludge. The reaction was then let go for 120 hours after which the gas production seemed to level off. 


\section{Procedure for colorimetry analysis}

The COD and ammonia concentration of each wastewater sample dosed with polymer was measured by colorimetry using a spectrophotometer. Tests vials pre-loaded with analytic reagents, Hach vial TNT 822 for COD and Hach vial TNT 830 for ammonia were used for the colorimetry analysis.

\section{Procedure for UV-Vis analysis}

The UV-Vis absorbance method was used, for the detection of polymers in wastewater. The UV-Vis spectrometer was used to measure the absorbance of the wastewaters dosed with different amounts of polymer. The supernatant was then diluted by either $90 \%$ (1 part wastewater and 9 parts DI water) or by $80 \%$ (2 parts wastewater and 8 parts DI water). The wastewater was diluted to two different concentrations to compare the consistency in the absorbance values recorded. UV-Vis analysis was done for wastewater dosed with polymer before anaerobic digestion (pre digestion) and for wastewater dosed with polymer after anaerobic digestion (post digestion).

\section{Procedure for biogas quality analysis}

Biogas analysis was performed using a thermal conductivity detector (TCD) in the gas chromatograph (GC). The rich mixture inside the bottle reactor after the experimental run was analyzed in the $\mathrm{GC}$ to find out its methane and carbon dioxide concentrations. 


\section{RESULTS AND DISCUSSION}

\section{A. RESPIROMETER EXPERIMENT RESULTS}

When polymer was added to the wastewater, the dissolved solids in the wastewater separate out. The amount of solids settling differs for each polymer concentration. The total amount of dissolved solids in the wastewater was 1.02 grams. TABLE II below gives the amount (grams) of solid that separated out from $500 \mathrm{ml}$ of pre centrifuge wastewater and the percentage of dissolved solids lost.

\section{TABLE II}

\section{SUMMARY OF DISSOLVED SOLIDS LOST FROM THE WASTEWATER FOLLOWING ADDITION OF POLYMER}

\begin{tabular}{|c|c|c|c|}
\hline Reactor & Polymer Conc & Grams & \% lost \\
\hline 1 & $1 \mathrm{mg} / \mathrm{L}$ & 0.016 & 1.5 \\
\hline 3 & $2.5 \mathrm{mg} / \mathrm{L}$ & 0.027 & 2.6 \\
\hline 4 & $5 \mathrm{mg} / \mathrm{L}$ & 0.0645 & 3.2 \\
\hline 5 & $7.5 \mathrm{mg} / \mathrm{L}$ & 0.121 & 11.8 \\
\hline 6 & $10 \mathrm{mg} / \mathrm{L}$ & 0.054 & 2.7 \\
\hline
\end{tabular}

One has to speculate as to how much polymer may be lost when the solids separate out. The solids in the wastewater contribute to the total COD and, hence, the total biogas production as well. Looking at TABLE II above, not many solids were lost in terms of total percentage except for the sample which had polymer concentration of 7.5 $\mathrm{mg} / \mathrm{L}$ which was slightly above $10 \%$. The reason for higher amount of solids lost when the polymer concentration was at $7.5 \mathrm{mg} / \mathrm{L}$ was probably due to more efficient liquid solid separation at that polymer concentration. The decrease in biogas production from 
the polymer dosed wastewater samples was expected to be minimal when comparing the solids lost to actual amount of solids in the wastewater.

Three experimental tests were conducted with similar conditions on the respirometer. The testing was stopped after 120 hours as the biogas production appeared to level off in each case. FIGURE 6 below shows the average biogas production volume for the three different tests. The average biogas production was also accompanied by error bars to show the variation in the three different tests.

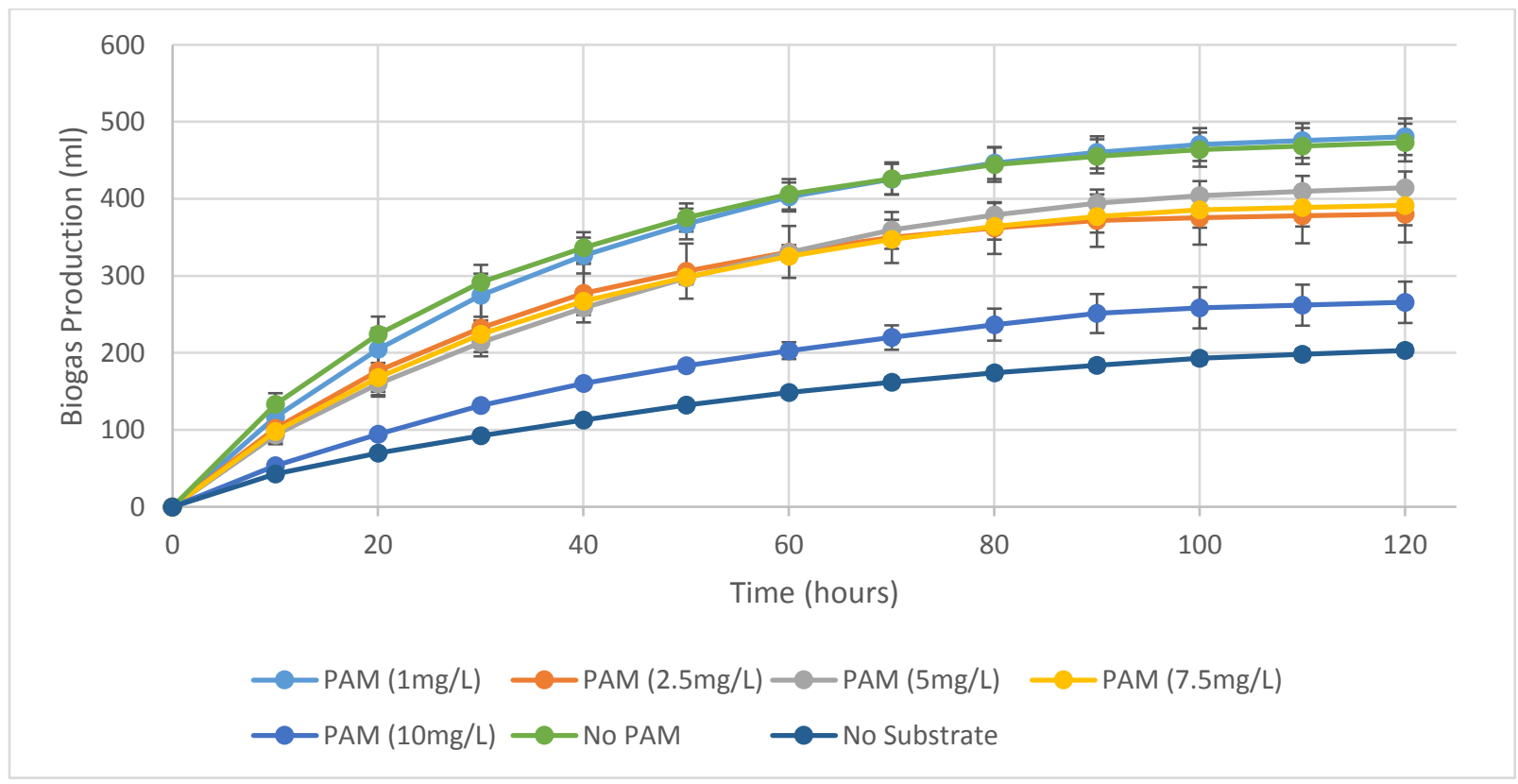

FIGURE 6 - Average biogas production as a function of time from the three different respirometry tests.

TABLE III below provides a snapshot of the average gas production rates from the three tests and for all different wastewater samples. 
TABLE III

BIOGAS PRODUCTION VOLUMES FROM DIFFERENT PAM CONCENTRATIONS

\begin{tabular}{|l|r|r|r|r|}
\hline \multirow{2}{*}{$\begin{array}{c}\text { Polymer } \\
\text { Concentration }\end{array}$} & \multicolumn{4}{|c|}{ Biogas Production Volume (ml) } \\
\cline { 2 - 5 } & \multicolumn{1}{|c|}{ Test 1} & \multicolumn{1}{c|}{ Test 2 } & \multicolumn{1}{c|}{ Test 3 } & \multicolumn{1}{c|}{ Average } \\
\hline PAM $(1 \mathrm{mg} / \mathrm{L})$ & 535.9 & 382.0 & 524.0 & 480.6 \\
\hline PAM $(2.5 \mathrm{mg} / \mathrm{L})$ & 365.4 & 255.7 & 519.5 & 380.2 \\
\hline PAM $(5 \mathrm{mg} / \mathrm{L})$ & 486.5 & 334.4 & 422.2 & 414.4 \\
\hline PAM $(7.5 \mathrm{mg} / \mathrm{L})$ & 498.7 & 349.2 & 326.8 & 391.6 \\
\hline PAM $(10 \mathrm{mg} / \mathrm{L})$ & 366.2 & 173.0 & 257.7 & 265.6 \\
\hline No PAM & 540.0 & 373.1 & 506.3 & 473.1 \\
\hline No Substrate & 179.7 & 199.0 & 230.7 & 203.1 \\
\hline
\end{tabular}

The biogas production levels for the second respirometer run were lower than the first and the third test. This was because the waste water characteristics and hence the initial COD content can change day to day depending on blend changes.

A t-test analysis was performed to see if the biogas production volumes from the different PAM concentrations were statistically different from the biogas production with no PAM in it. The t-test is a statistical analysis of two populations. In this case, the control group which was the sample with no PAM was compared to the samples containing PAM. The t-test was performed assuming unequal variances with a $95 \%$ confidence level. The t-test analysis concluded that biogas production values for samples with PAM is not statistically different from the biogas production values of the sample with no PAM. 


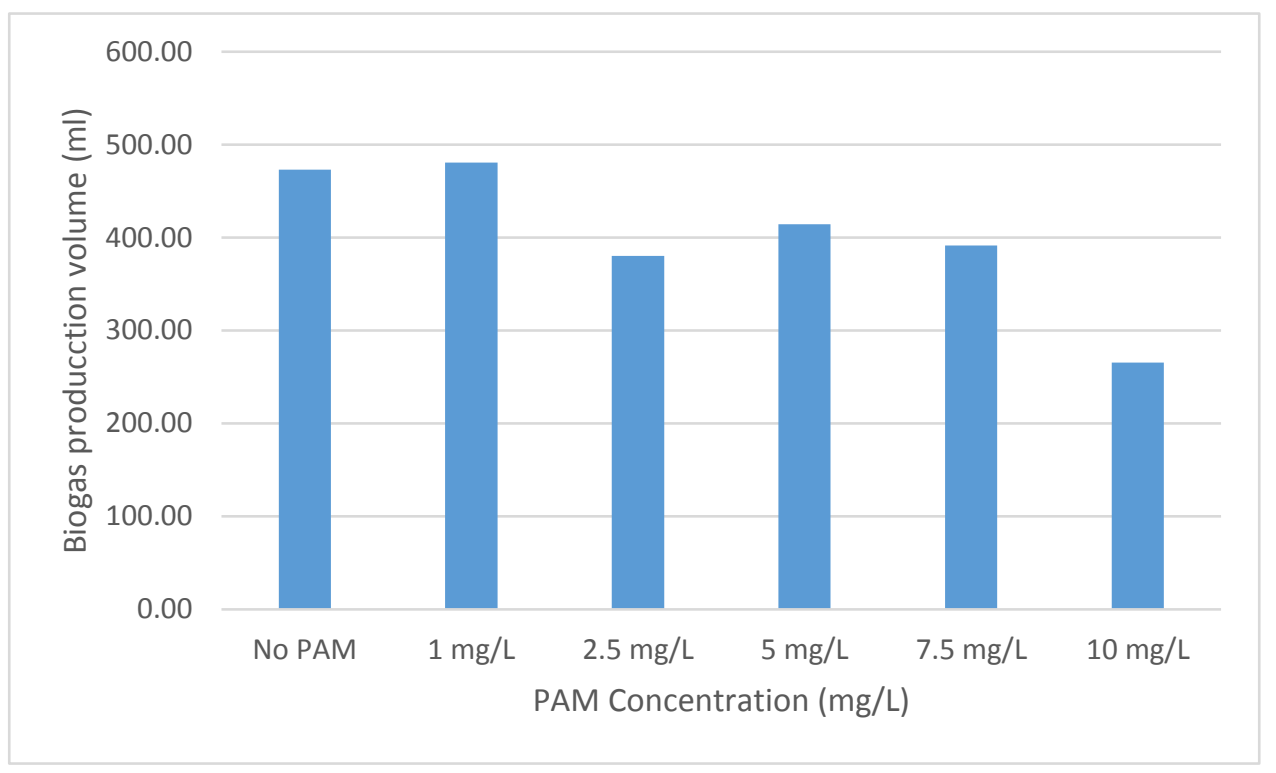

FIGURE 7 - Biogas production as a function of PAM concentration

FIGURE 7 above shows the total biogas production from the different wastewater samples. The total biogas production of the wastewater sample dosed with $1 \mathrm{mg} / \mathrm{L}$ was slightly higher than the wastewater sample with no polymer addition. There was a decrease in biogas production for the reactors where PAM had been added, especially for the reactors where the polymer addition was equal to or greater than $2.5 \mathrm{mg} / \mathrm{L}$. TABLE IV below shows the percent of biogas production in the reactor with polymer when compared to the biogas production with no polymer. 
TABLE IV

BIOGAS PRODUCTION AS A FUNCTION OF PAM CONCENTRATION

\begin{tabular}{|l|c|}
\hline & $\begin{array}{c}\text { \% of Biogas production } \\
\text { with no PAM }\end{array}$ \\
\hline PAM $(1 \mathrm{mg} / \mathrm{L})$ & 102 \\
\hline PAM $(2.5 \mathrm{mg} / \mathrm{L})$ & 80 \\
\hline PAM $(5 \mathrm{mg} / \mathrm{L})$ & 88 \\
\hline PAM $(7.5 \mathrm{mg} / \mathrm{L})$ & 83 \\
\hline PAM $(10 \mathrm{mg} / \mathrm{L})$ & 56 \\
\hline
\end{tabular}

For the reactor where $1 \mathrm{mg} / \mathrm{L}$ of PAM had been added, the biogas production was comparable to the biogas production where no PAM was added even though the biogas production was slightly higher. For the reactors where PAM was added between 2.5 $\mathrm{mg} / \mathrm{L}$ to $7.5 \mathrm{mg} / \mathrm{L}$, the biogas production rate was between $80 \%$ to $88 \%$ of the biogas production where no PAM was added. The biogas production for the reactor where 10 $\mathrm{mg} / \mathrm{L}$ of PAM was added was at $56 \%$ of the biogas production where no PAM was added.

As pointed out earlier the addition of polymer into the wastewater removed a small percentage of solids from the wastewater which can contribute to biogas production. As in TABLE II, for reactors where the concentration of polymer added was between $1 \mathrm{mg} / \mathrm{L}$ to $7.5 \mathrm{mg} / \mathrm{L}$ the loss of solids was between 1 to $3 \%$. This clearly shows that the addition of polymer does hinder the anaerobic digestion mechanism as the percentage of solids lost does not compare to the decrease in biogas production. For the 
reactor where $10 \mathrm{mg} / \mathrm{L}$ of polymer was added, there was a loss of solids by $11 \%$ and the biogas production was at $56 \%$ when compared to biogas production with no PAM.

Dentel et al. (2000) pointed out that the polymer can end up binding with the substrate, which can limit the anaerobic bacteria's access to energy and nutrients, which can decrease the overall efficiency of anaerobic digestion. Gossett et al. (1978) observed that $475 \mathrm{mg} / \mathrm{L}$ of the cationic polymer epichlorohydrin / dimethylamine (EPI-DMA) added in primary clarification decreased gas production in an anaerobic digester. According to Gossett et al., this was evidently due to decreased sludge biodegradability. In other words, polymer binding to the substrate was seen as the cause of reduced anaerobic digestion.

Also as pointed out by Yang (2011), when the concentration of polyacrylamide was above $1 \mathrm{mg} / \mathrm{L}$, it had negative effects on the removal of COD. This was attributed to the bad settleability and lower microbial activity of the sludge, which was attributed to competition during bridging between polyacrylamide polymers.

The role of the cationic PAM was to increase the adsorption of flocculants on the surface of sludge particles by diminishing the negative charge of the sludge particles. However, higher amount of PAM can lead to competition during bridging between the flocculants and can adversely affect the surface of the sludge particle. This can lead to lower microbial activity of the sludge and hence result in lower biogas production.

From the data presented so far it seems that the polymer addition was inhibiting biogas production. To further substantiate this theory, two more types of analysis were 
performed. The first analysis measured the COD before and after anaerobic digestion in the respirometer. The second analysis compared the theoretical biogas production values based on the COD content in the reactors and compare it with the actual biogas production values.

\section{B. COD DIGESTION ANALYSIS}

After PAM was added to the wastewater samples, the solids that settled out were removed. The wastewater samples that were dosed with PAM were then added to the bottle reactor along with the sludge that contains the bacteria. The initial COD from each of the bottle reactors was then measured. The final COD was measured from the bottle reactors at the end of the respirometry tests. TABLE V below gives a snapshot of the COD reduction for the different respirometer reactors.

\section{TABLE V}

SUMMARY OF COD REDUCTION AS A FUNCTION OF PAM CONCENTRATION

\begin{tabular}{|r|r|r|r|}
\hline \multicolumn{4}{|c|}{ COD Digestion } \\
\hline & Initial (mg/L) & Final (mg/L) & Digestion (\%) \\
\hline No PAM & 2402 & 1092 & 54.5 \\
\hline PAM (1mg/L) & 2376 & 1123 & 52.7 \\
\hline PAM (2.5mg/L) & 2254 & 1324 & 41.2 \\
\hline PAM (5mg/L) & 2202 & 1238 & 43.7 \\
\hline PAM (7.5mg/L) & 2117 & 1146 & 45.8 \\
\hline PAM (10mg/L) & 1737 & 1122 & 35.4 \\
\hline No Substrate & 702 & 657 & 6.4 \\
\hline
\end{tabular}


The trend was similar to the trend in biogas production volumes for the different reactors. The highest COD reduction was for the reactor with no PAM, which was at $54 \%$. For the reactor where PAM was added at $1 \mathrm{mg} / \mathrm{L}$, the COD reduction was at $52 \%$. For the reactors where PAM was added between $2.5 \mathrm{mg} / \mathrm{L}$ to $7.5 \mathrm{mg} / \mathrm{L}$, the COD reduction was between $41 \%$ to $45 \%$. The COD reduction for the reactor where $10 \mathrm{mg} / \mathrm{L}$ of PAM was added was at 35\%, which was the least and follows the biogas production trend. This data correlates to the observation made by Chang (2001) that when the concentration of polyacrylamide was above $1 \mathrm{mg} / \mathrm{L}$ it had negative effects on the removal of COD.

\section{THEORETICAL BIOGAS PRODUCTION COMPARISON}

Based on the amount of COD present in the substrate, theoretical biogas production can be calculated. The theoretical biogas production values can then be compared to actual biogas production values to see if there was a drop off in biogas production in the reactors that were dosed with polymer.

One pound of COD is equal to 5.62 cubic feet of methane $\left(\mathrm{CH}_{4}\right)$ per Perry (1964). This equated to $0.35 \mathrm{~L}$ of methane for every gram of COD digested. Biogas is a mixture of methane and carbon dioxide. Methane content in biogas can vary from 50 to $80 \%$. For the purpose of theoretical biogas volume calculations, methane was assumed to be $75 \%$ of the biogas and the remaining carbon dioxide. This value was used as a conservative estimate for the theoretical calculations; the actual methane percent determined by GC 
analysis was 78\%. TABLE VI below shows the theoretical biogas volumes calculated from the measured COD for each bottle reactor.

\section{TABLE VI}

THEORETICAL BIOGAS PRODUCTION AS A FUNCTION OF PAM BASED ON COD LOADING

\begin{tabular}{|l|r|r|r|}
\hline \multicolumn{1}{|c|}{ Reactor } & COD Loading $(\mathrm{g})$ & Methane Production $(\mathrm{ml})$ & Biogas Production $(\mathrm{ml})$ \\
\hline PAM $(1 \mathrm{mg} / \mathrm{L})$ & 1.19 & 416 & 554 \\
\hline PAM $(2.5 \mathrm{mg} / \mathrm{L})$ & 1.13 & 394 & 526 \\
\hline PAM $(5 \mathrm{mg} / \mathrm{L})$ & 1.10 & 385 & 514 \\
\hline PAM $(7.5 \mathrm{mg} / \mathrm{L})$ & 1.06 & 370 & 494 \\
\hline PAM $(10 \mathrm{mg} / \mathrm{L})$ & 0.87 & 304 & 405 \\
\hline No PAM & 1.20 & 420 & 560 \\
\hline No Substrate & 0.35 & 123 & 164 \\
\hline
\end{tabular}

TABLE VII lists the theoretical and actual biogas production volumes for the different bottle reactors. The theoretical biogas volume was higher than the actual biogas volumes recorded by the respirometer. Table VII also calculates the percentage of actual biogas production with respect to theoretical biogas production.

\section{TABLE VII}

COMPARISON OF ACTUAL AND THEORETICAL BIOGAS VOLUME

\begin{tabular}{|l|r|r|r|}
\hline \multicolumn{1}{|c|}{ Reactor } & $\begin{array}{c}\text { Biogas Volume from } \\
\text { respirometer }(\mathrm{ml})\end{array}$ & $\begin{array}{c}\text { Theoretical Biogas } \\
\text { volume }(\mathrm{ml})\end{array}$ & $\begin{array}{c}\text { Percentage of } \\
\text { Theoretical (\%) }\end{array}$ \\
\hline PAM $(1 \mathrm{mg} / \mathrm{L})$ & 481 & 554 & 87 \\
\hline PAM $(2.5 \mathrm{mg} / \mathrm{L})$ & 380 & 526 & 72 \\
\hline PAM $(5 \mathrm{mg} / \mathrm{L})$ & 414 & 514 & 81 \\
\hline PAM $(7.5 \mathrm{mg} / \mathrm{L})$ & 392 & 494 & 66 \\
\hline PAM $(10 \mathrm{mg} / \mathrm{L})$ & 266 & 405 & 84 \\
\hline No PAM & 473 & 560 & 124 \\
\hline No Substrate & 203 & 164 & \\
\hline
\end{tabular}


For the bottle reactors with no PAM and where $1 \mathrm{mg} / \mathrm{L}$ of PAM had been added, the percentage of actual biogas production with respect to the theoretical biogas production was $84 \%$ and $87 \%$. For the bottle reactors where polymer had been added between $2.5 \mathrm{mg} / \mathrm{L}$ and $7.5 \mathrm{mg} / \mathrm{L}$, the percentage of actual biogas production with respect to theoretical biogas production was 72,81 and $79 \%$. For the bottle reactor where polymer had been added by $10 \mathrm{mg} / \mathrm{L}$, the percentage of actual biogas production with respect to theoretical biogas production was $66 \%$.

There was a lower production rate between the percentage of actual biogas production with respect to theoretical biogas production for the bottle reactors that are dosed with polymer at $2.5 \mathrm{mg} / \mathrm{L}$ or greater. This data once again supports the theory that polymer in the waste water was hindering anaerobic digestion.

All analysis results points to the conclusion that residual polymer above a concentration of $1 \mathrm{mg} / \mathrm{L}$ in the wastewater hinders anaerobic digestion.

\section{BIOGAS QUALITY ANALYSIS}

Another area of concern was whether the polymer in the wastewater would decrease the quality of methane in the biogas. Biogas analysis was performed to determine the methane and carbon dioxide content. The biogas rich mixture inside the bottle reactor after the experimental test was analyzed. TABLE VIII below shows the methane and carbon dioxide quality in the biogas. 


\section{TABLE VIII}

\section{METHANE AND CARBON DIOXIDE QUALITY IN THE BIOGAS}

\begin{tabular}{|l|c|c|}
\hline \multirow{2}{*}{\multicolumn{1}{|c|}{ Reactor }} & \multicolumn{2}{c|}{ Quality } \\
\cline { 2 - 3 } & $\begin{array}{c}\mathrm{CH} 4 \\
(\%)\end{array}$ & $\begin{array}{c}\mathrm{CO} 2 \\
(\%)\end{array}$ \\
\hline Polymer $(1 \mathrm{mg} / \mathrm{L})$ & 77.9 & 22.0 \\
\hline Polymer $(2.5 \mathrm{mg} / \mathrm{L})$ & 78.3 & 21.7 \\
\hline Polymer $(5 \mathrm{mg} / \mathrm{L})$ & 78.1 & 21.8 \\
\hline Polymer $(7.5 \mathrm{mg} / \mathrm{L})$ & 78.9 & 21.0 \\
\hline Polymer $(10 \mathrm{mg} / \mathrm{L})$ & 78.7 & 21.2 \\
\hline No Polymer & 76.4 & 23.5 \\
\hline
\end{tabular}

There was a slight increase $(>2 \%)$ in methane concentration for the wastewater samples with polymer. This was not a big enough change to conclude that there was an impact in the quality of methane in the biogas from the polymer in the wastewater. based on the data, the conclusion was that the polymer does not affect the quality of biogas produced from the wastewater.

\section{E. POLYMER DETECTION IN WASTEWATER}

UV-Vis analysis was performed for wastewater dosed with polymer before anaerobic digestion (pre digestion) and for wastewater dosed with polymer after anaerobic digestion (post digestion).

The absorbance data shown in the figures below was over a wavelength of 320 to $670 \mathrm{~nm}$. This range was chosen because this was where the absorbance values showed the biggest change for the different wastewater samples. FIGURE 8 shows the absorbance measurements for the pre digestion waste water samples dosed with polymer diluted by $90 \%$ (1 part wastewater and 9 parts DI water). FIGURE 9 shows the 
absorbance measurements for the post digestion waste water samples dosed with polymer diluted by $90 \%$ (1 part wastewater and 9 parts DI water). FIGURE 10 shows the absorbance measurements for the pre digestion waste water samples dosed with polymer diluted by $80 \%$ ( 2 part wastewater and 8 parts DI water). FIGURE 11 shows the absorbance measurements for the pre digestion waste water samples dosed with polymer diluted by $80 \%$ (2 part wastewater and 8 parts DI water).

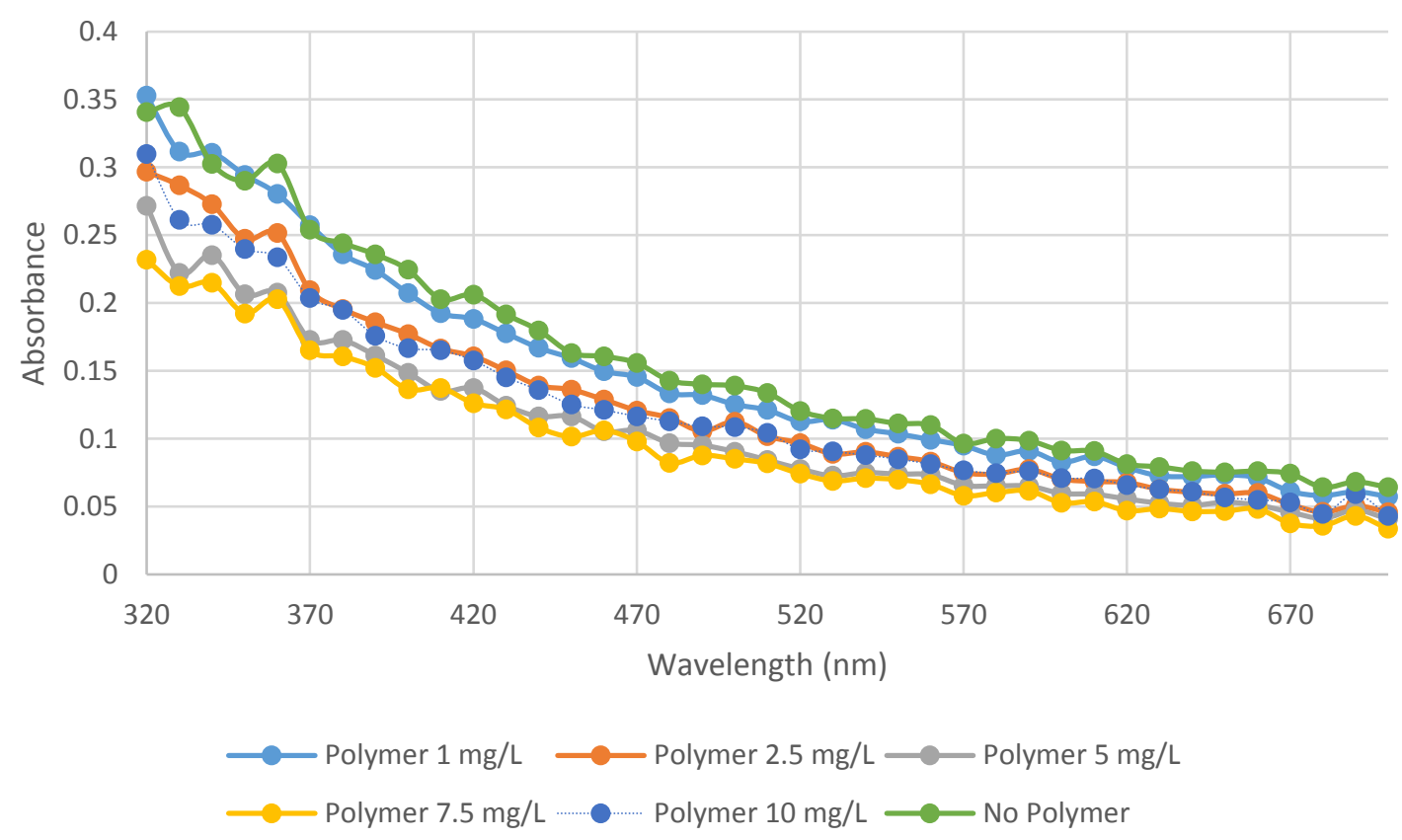

FIGURE 8 - Absorbance data for pre digestion wastewater samples diluted by $90 \%$ (1 part wastewater and 9 parts DI water) 


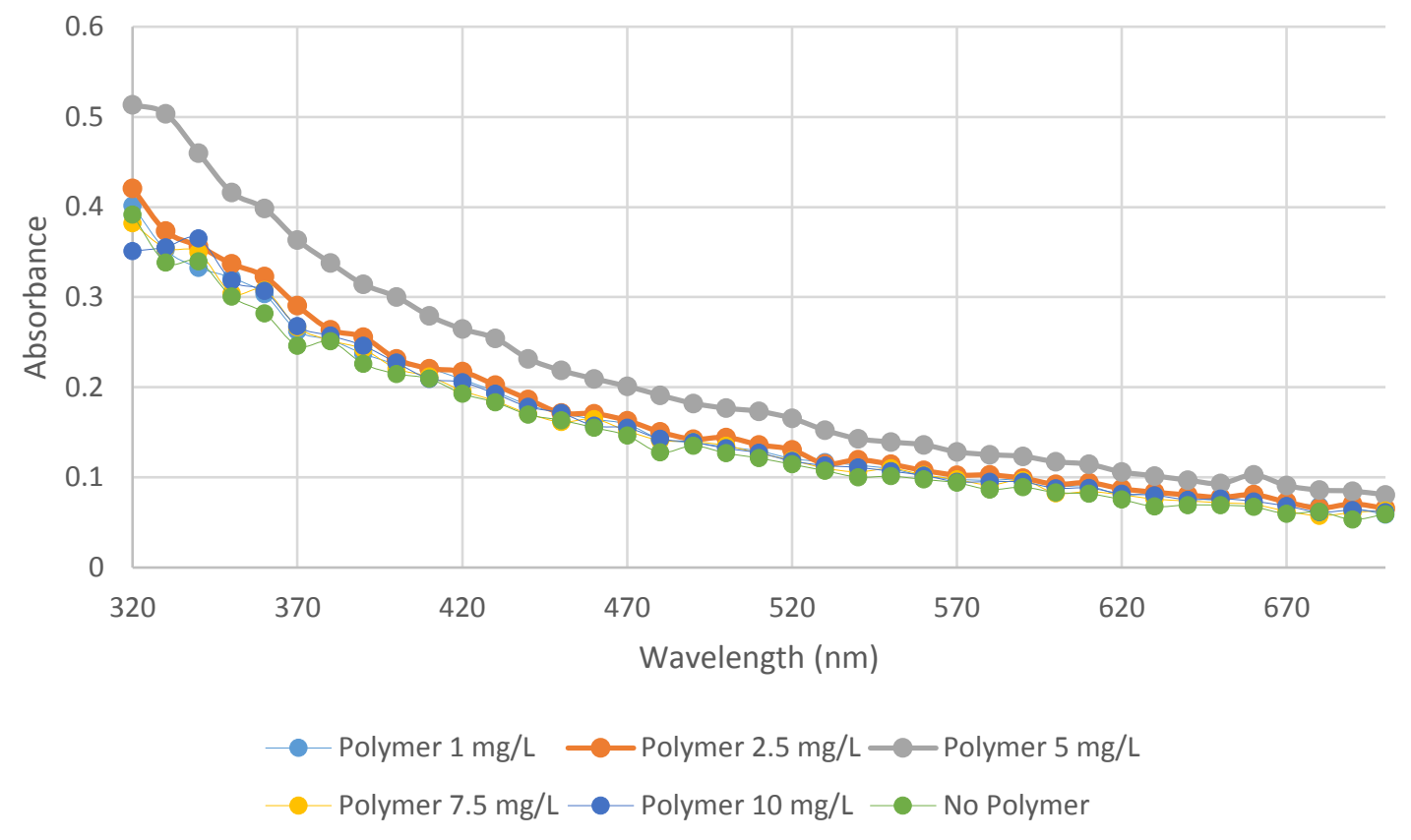

FIGURE 9 - Absorbance data for post digestion wastewater samples diluted by $90 \%$ (1 part wastewater and 9 parts DI water)

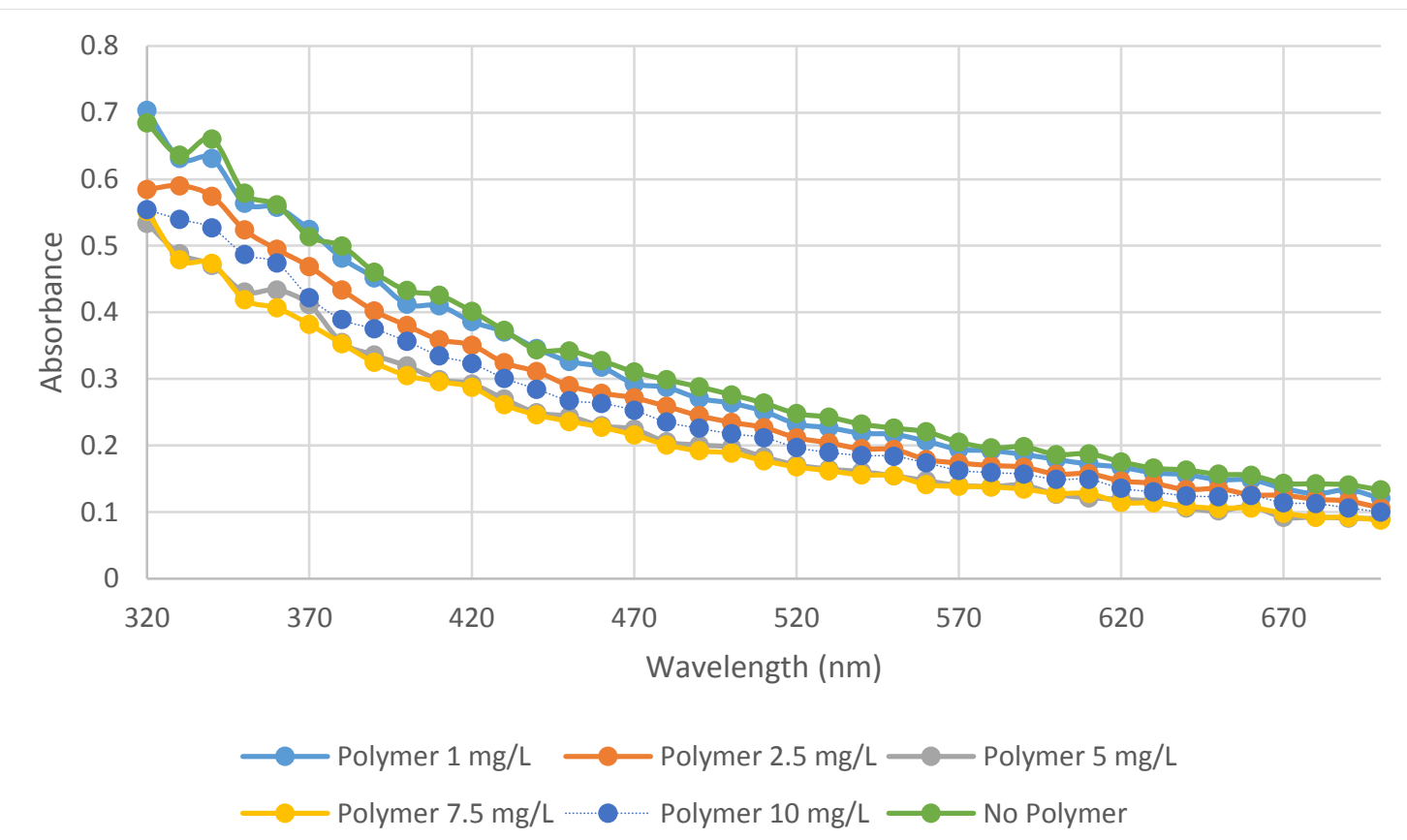

FIGURE 10 - Absorbance data for pre digestion wastewater samples diluted by $80 \%$ (2 parts wastewater and 8 parts DI water) 


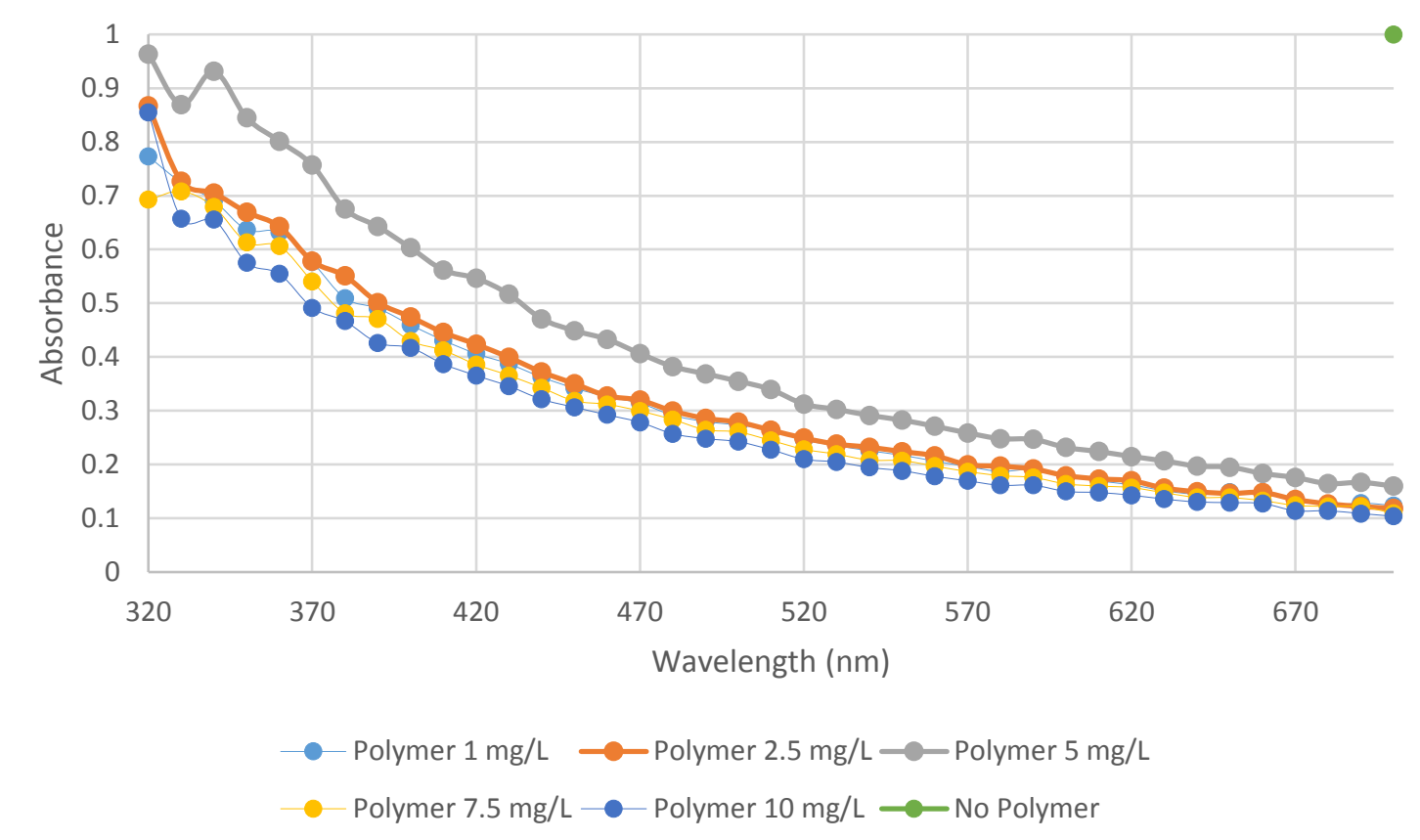

FIGURE 11 - Absorbance data for post digestion wastewater samples diluted by $80 \%$ (2 parts wastewater and 8 parts DI water)

As discussed in the earlier part of this section, the main objective of the UV-Vis measurements was to see the change in absorbance values before and after anaerobic digestion. FIGURES 12 to 17 shows the absorbance values for the different wastewater samples dosed with polymer that had been diluted by $90 \%$ (1 part wastewater and 9 parts DI water). 


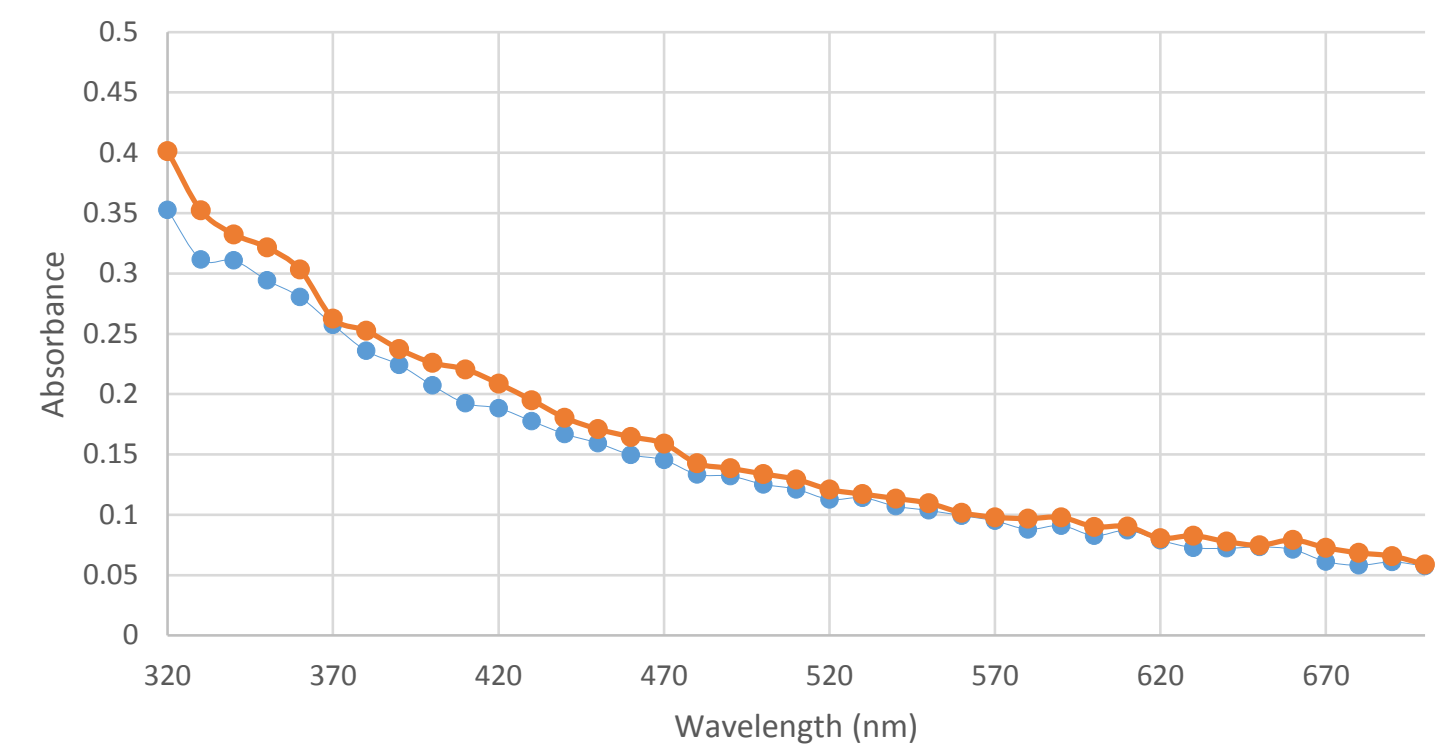

- Polymer $1 \mathrm{mg} / \mathrm{L}$ PreDigestion $\quad \longrightarrow$ Polymer $1 \mathrm{mg} / \mathrm{L}$, PostDigestion

FIGURE 12 - Comparison of pre and post digestion absorbance at $1 \mathrm{mg} / \mathrm{L}$ for $90 \%$ dilution

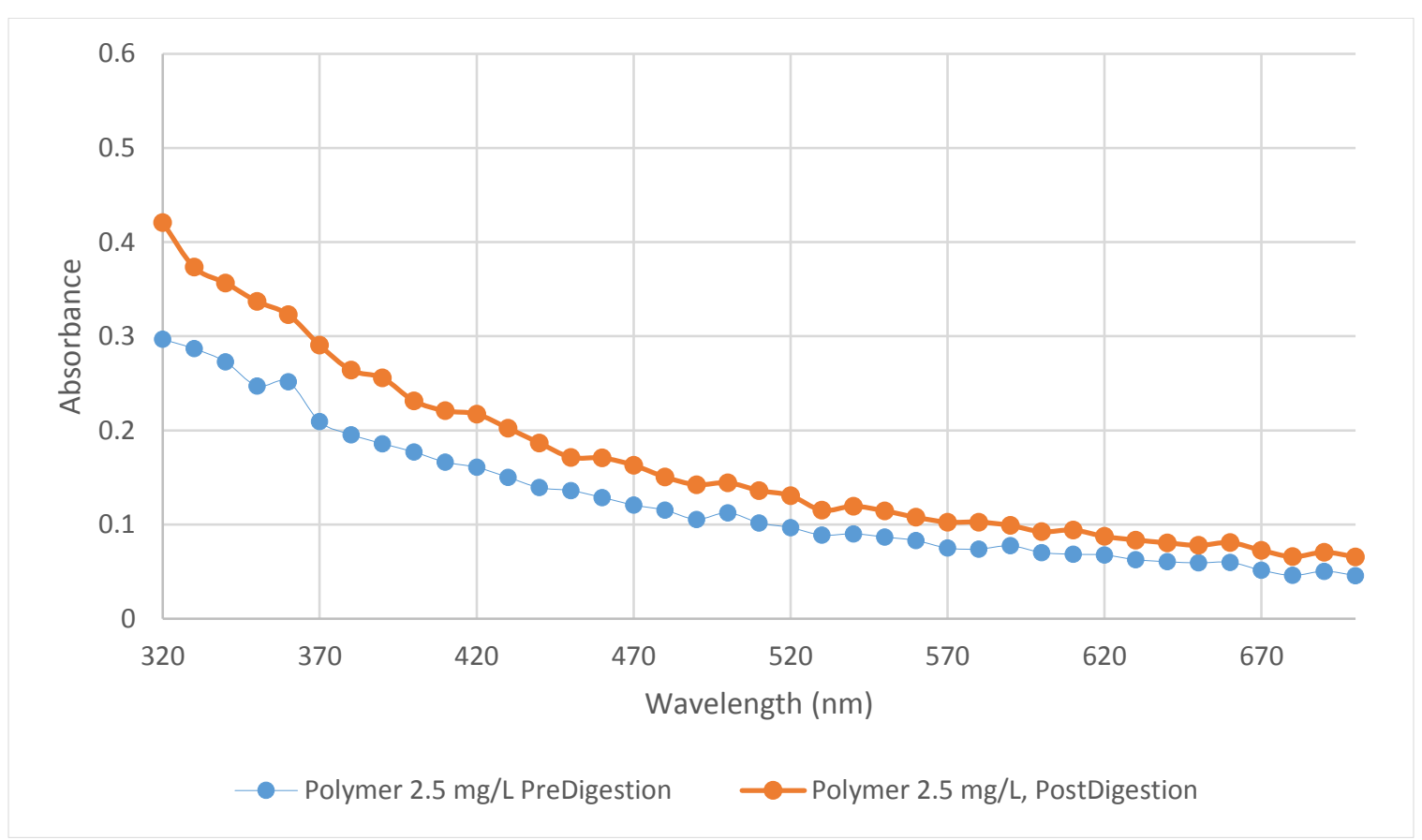

FIGURE 13 - Comparison of pre and post digestion absorbance at $2.5 \mathrm{mg} / \mathrm{L}$ for $90 \%$ dilution 


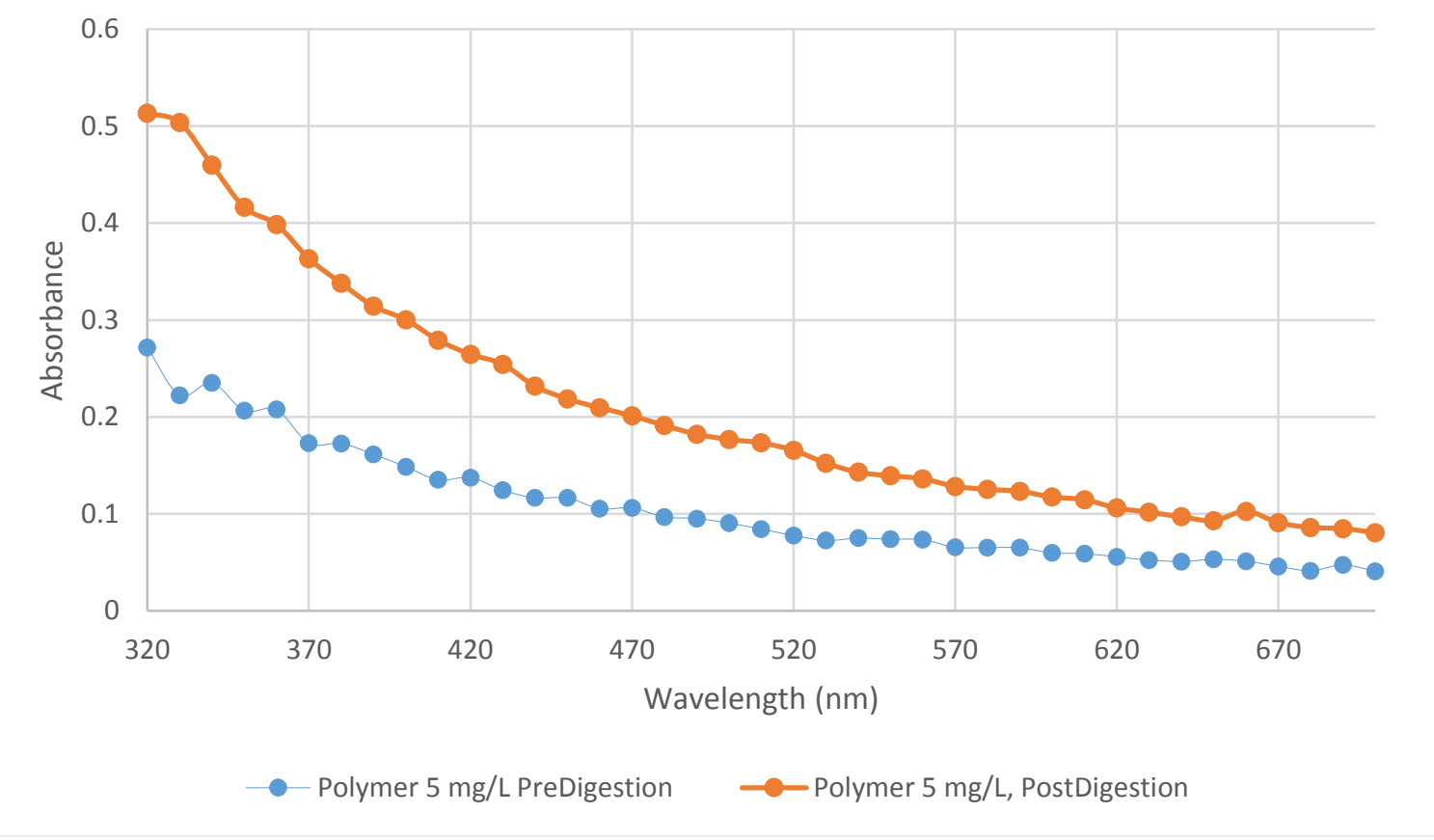

FIGURE 14 - Comparison of pre and post digestion absorbance at $5 \mathrm{mg} / \mathrm{L}$ for $90 \%$ dilution 


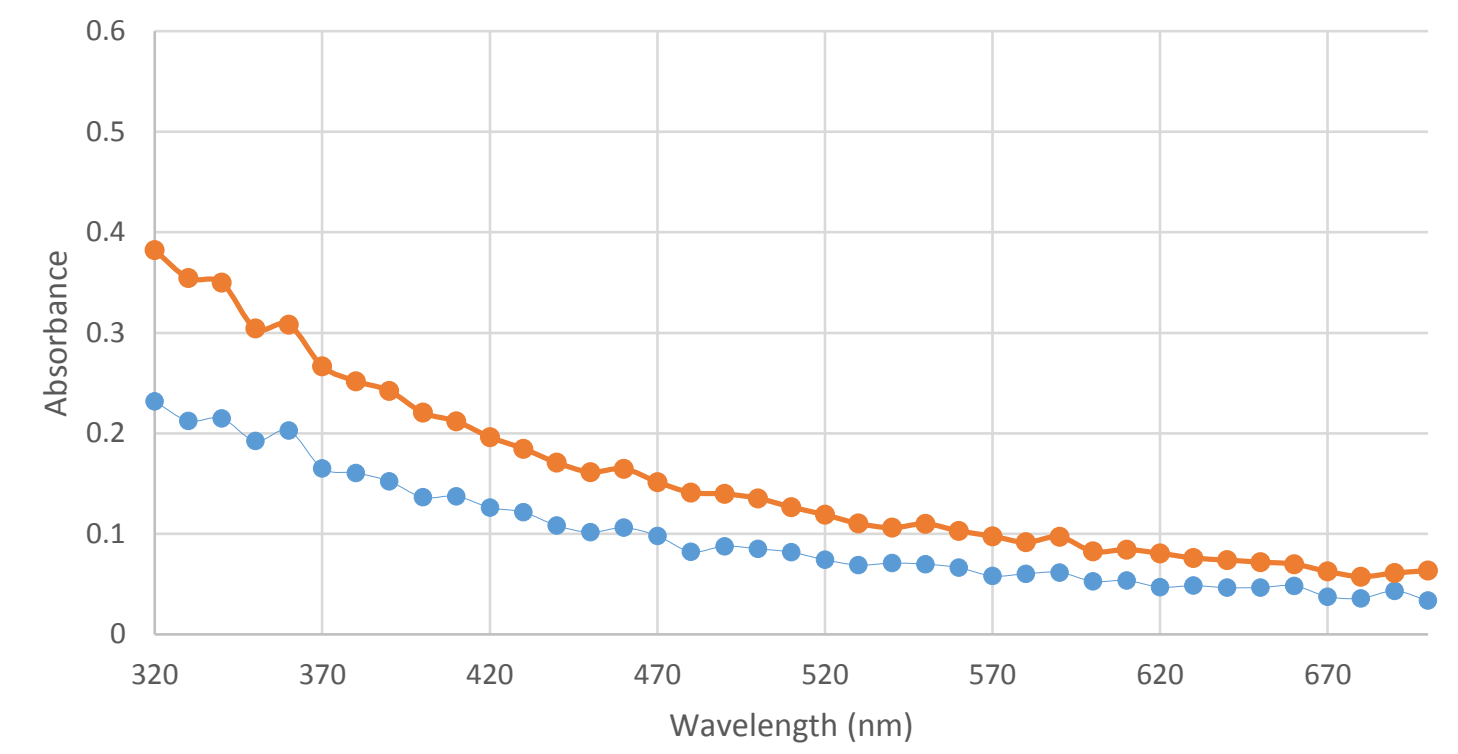

—- Polymer $7.5 \mathrm{mg} / \mathrm{L}$ PreDigestion $\quad \longrightarrow$ Polymer $7.5 \mathrm{mg} / \mathrm{L}$, PostDigestion

FIGURE 15 - Comparison of pre and post digestion absorbance at $7.5 \mathrm{mg} / \mathrm{L}$ for $90 \%$ dilution

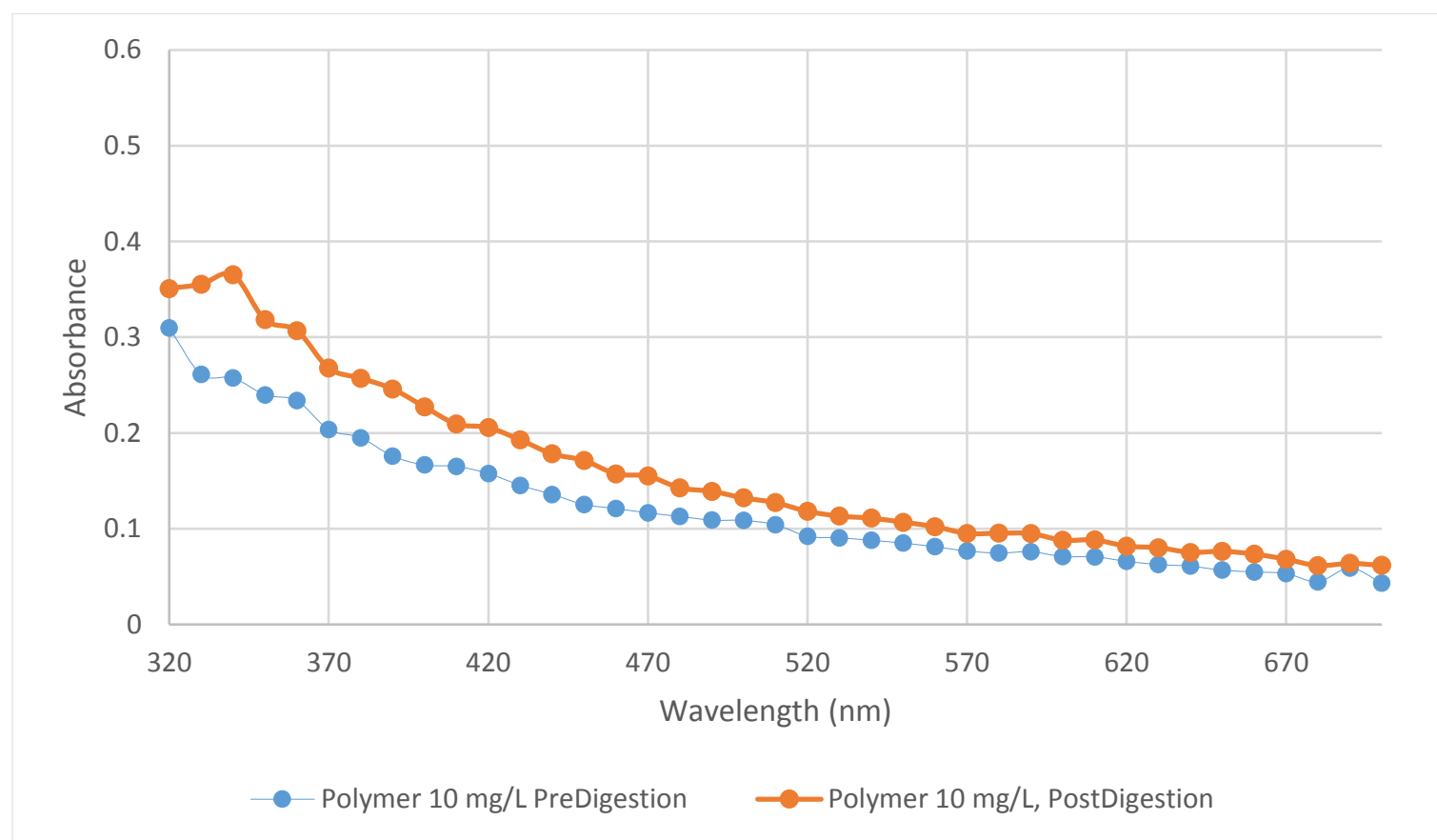

FIGURE 16 - Comparison of pre and post digestion absorbance at $10 \mathrm{mg} / \mathrm{L}$ for $90 \%$ dilution 


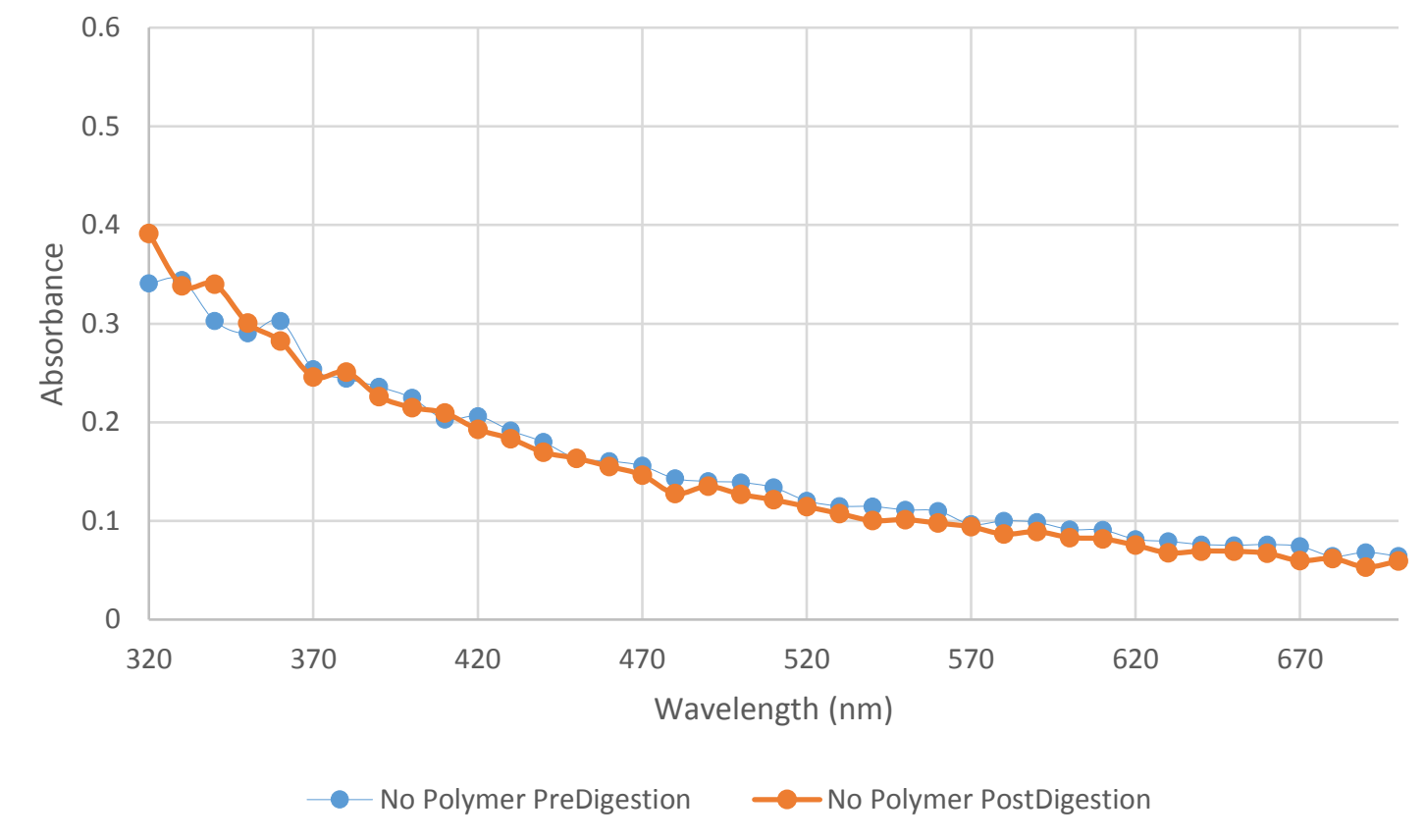

FIGURE 17 - Comparison of pre and post digestion absorbance at 90\% dilution for no polymer addition

FIGURES 18 to 23 shows the absorbance values for the different wastewater samples dosed with polymer that was diluted by $80 \%$ ( 2 part wastewater and 8 parts DI water). 


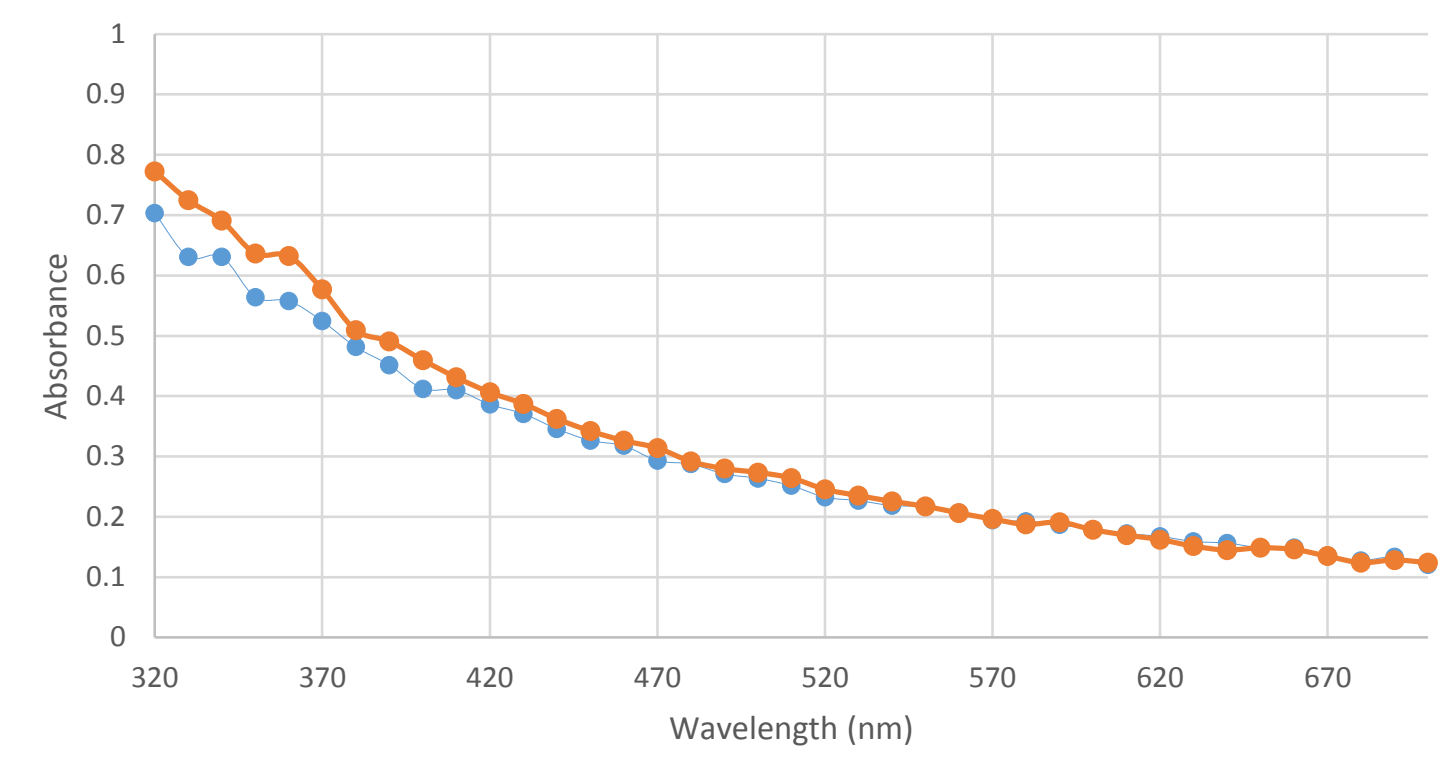

- Polymer $1 \mathrm{mg} / \mathrm{L}$ PreDigestion $\quad \longrightarrow$ Polymer $1 \mathrm{mg} / \mathrm{L}$, PostDigestion

FIGURE 18 - Comparison of pre and post digestion absorbance at $1 \mathrm{mg} / \mathrm{L}$ for $80 \%$ dilution

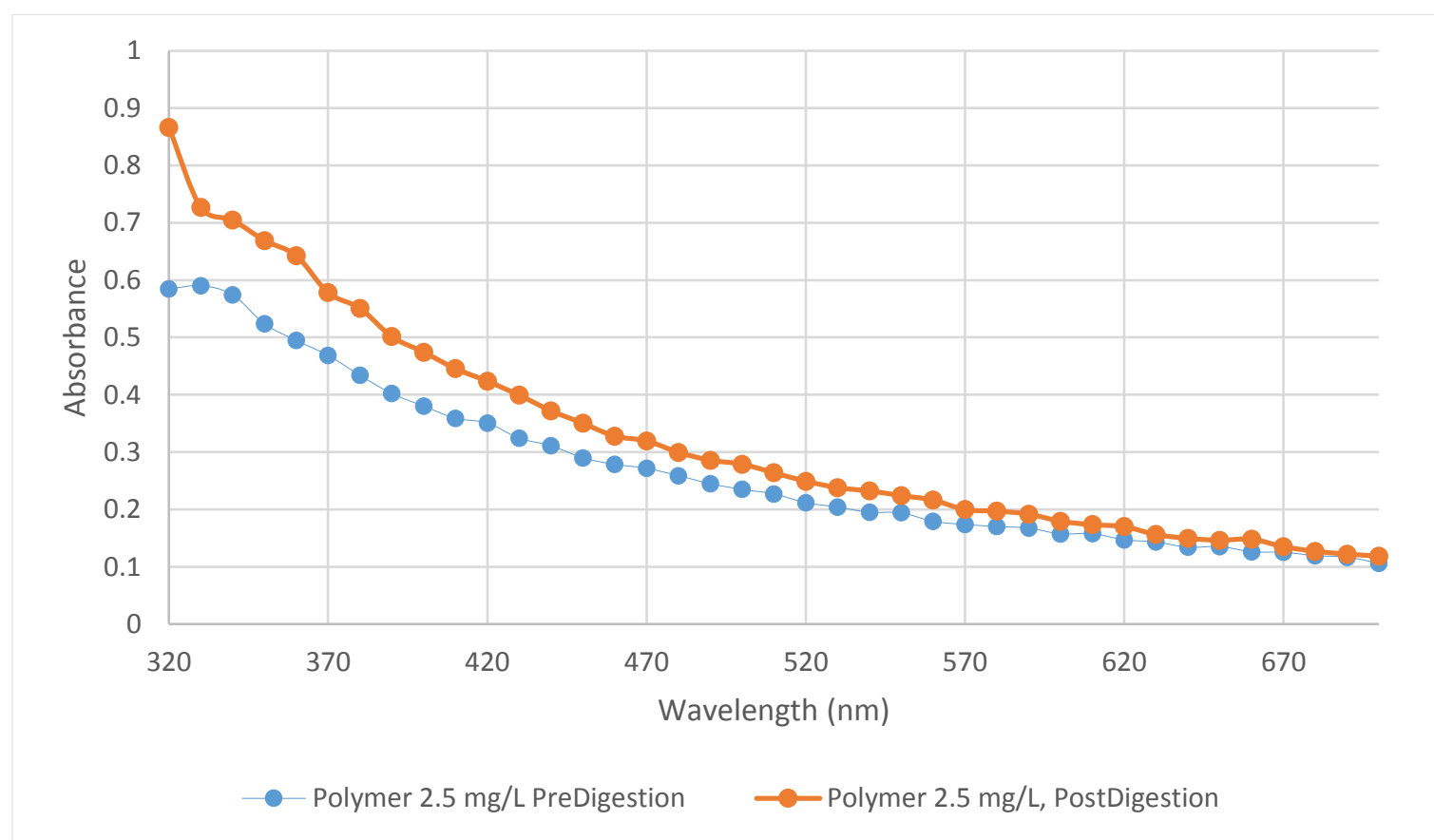

FIGURE 19 - Comparison of pre and post digestion absorbance at $2.5 \mathrm{mg} / \mathrm{L}$ for $80 \%$ dilution 


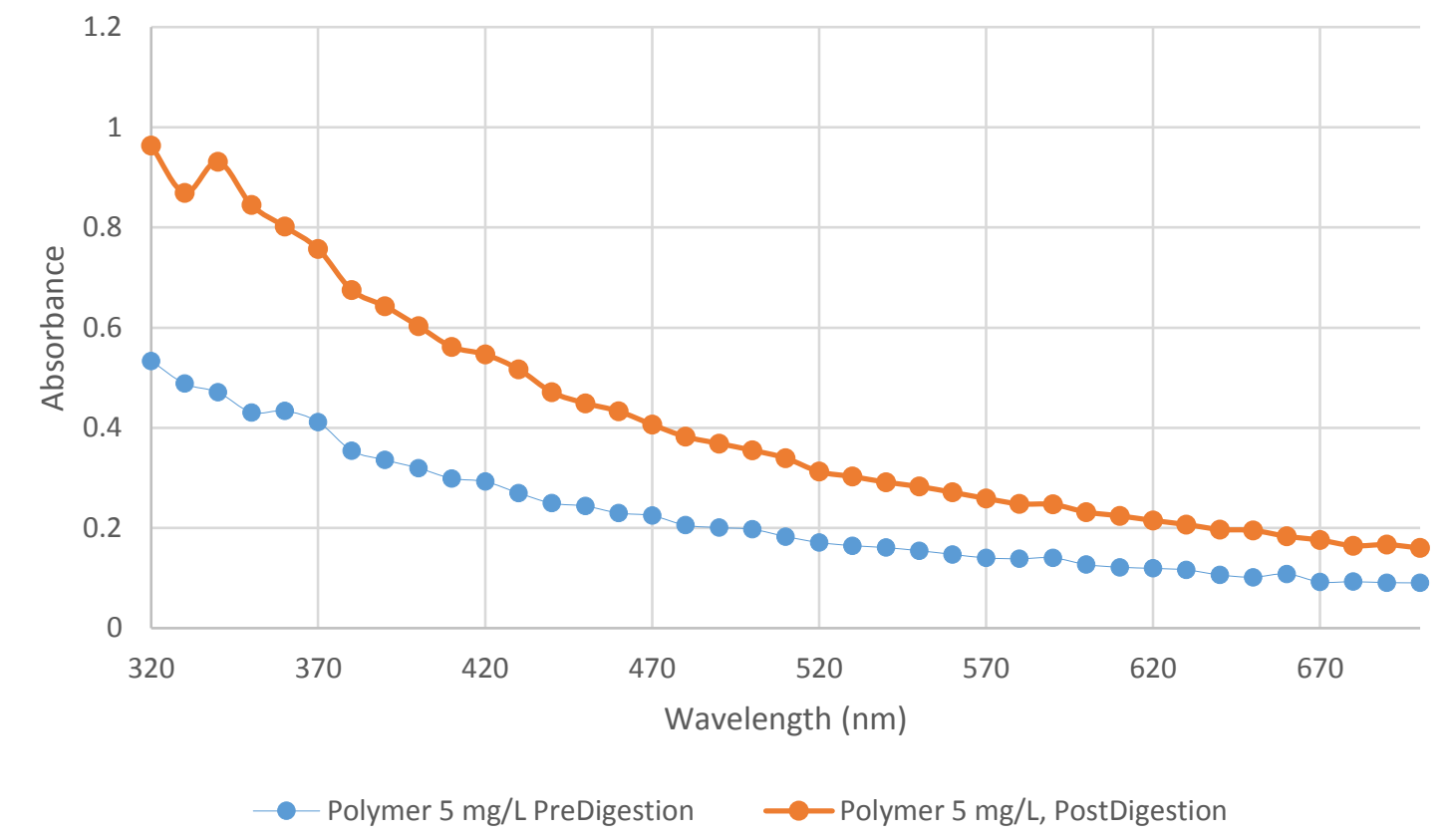

FIGURE 20 - Comparison of pre and post digestion absorbance at $5 \mathrm{mg} / \mathrm{L}$ for $80 \%$ dilution

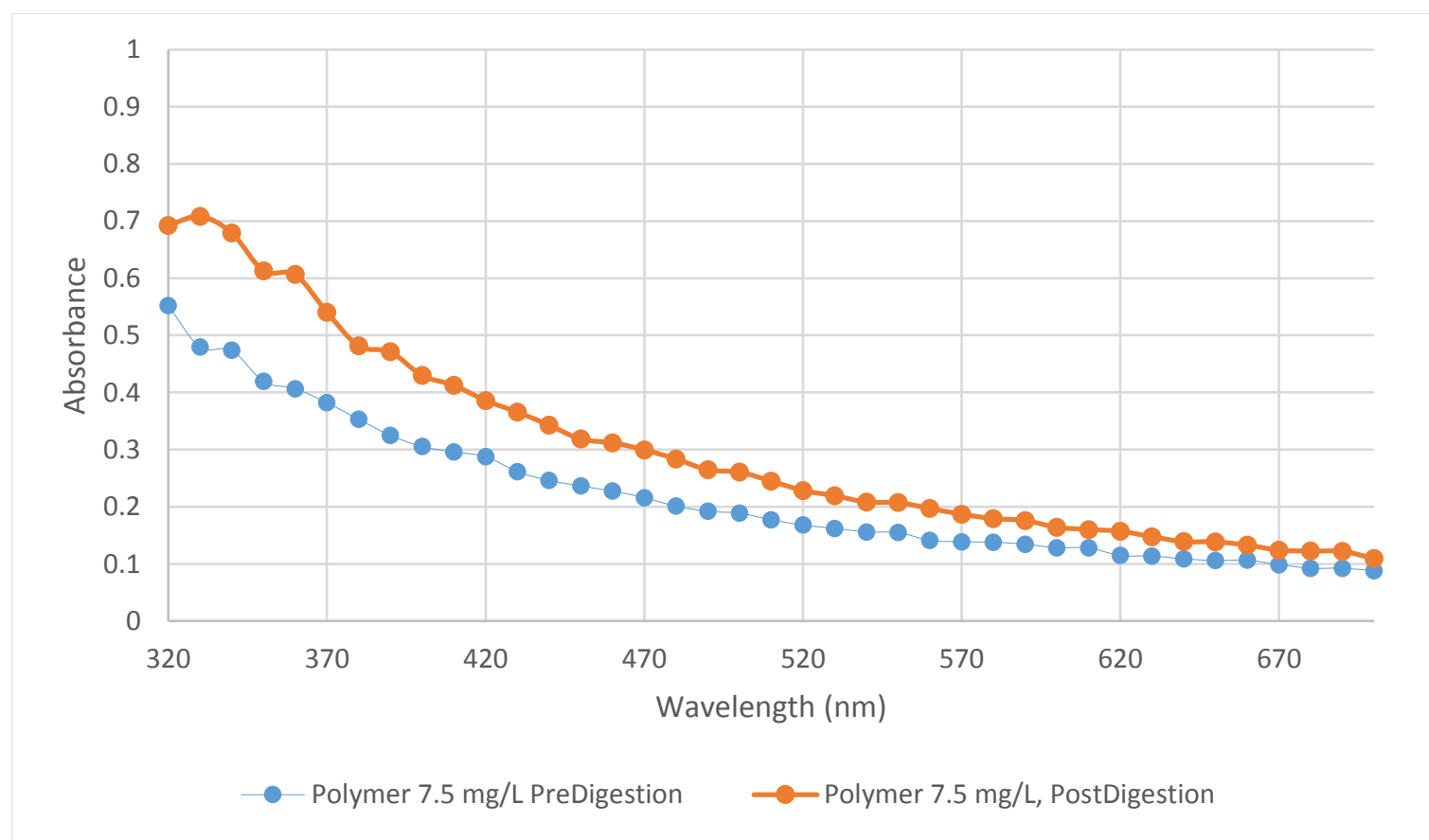

FIGURE 21 - Comparison of pre and post digestion absorbance at $7.5 \mathrm{mg} / \mathrm{L}$ for $80 \%$ dilution 


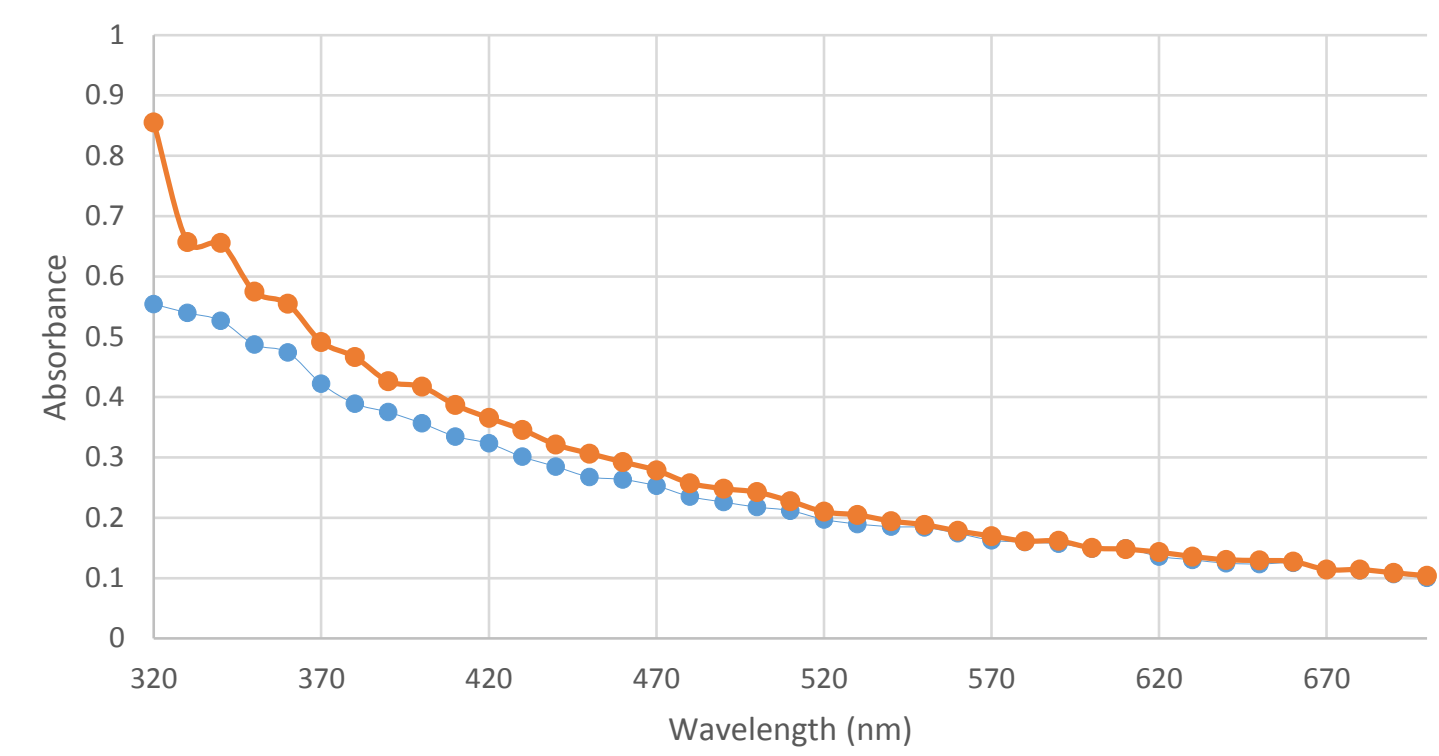

- Polymer $10 \mathrm{mg} / \mathrm{L}$ PreDigestion —Polymer $10 \mathrm{mg} / \mathrm{L}$, PostDigestion

FIGURE 22 - Comparison of pre and post digestion absorbance at $10 \mathrm{mg} / \mathrm{L}$ for $80 \%$ dilution

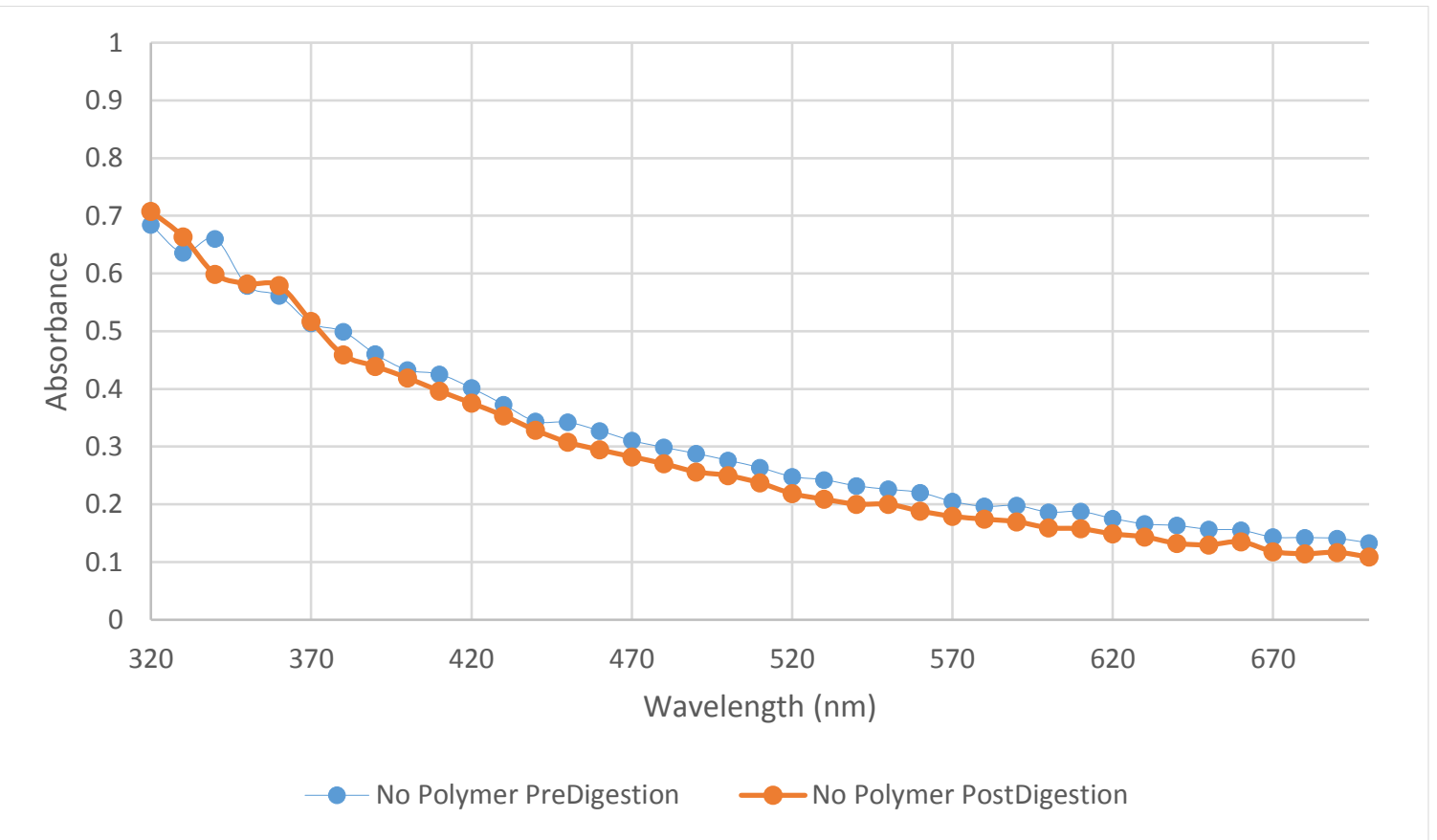

FIGURE 23 - Comparison of pre and post digestion absorbance at $80 \%$ dilution for no polymer addition 
The figures above show that the absorbance values of the post digestion wastewater samples were consistently higher than the absorbance values of the pre digestion wastewater samples. TABLE IX below quantifies the increase in absorbance values for the post digestion wastewater samples. The same trend of increase was seen in both the $90 \%$ and $80 \%$ dilution samples.

\section{TABLE IX}

\section{ABSORBANCE VALUE COMPARISON FOR PRE DIGESTION AND POST DIGESTION SAMPLES FOR 10\% AND 20\% DILUTION}

\begin{tabular}{|c|c|c|c|c|c|c|}
\hline & \multicolumn{3}{|c|}{$90 \%$ Dilution } & \multicolumn{3}{|c|}{$80 \%$ Dilution } \\
\hline & \multicolumn{2}{|c|}{$\begin{array}{c}\text { Average Absorbance } \\
\text { Values }\end{array}$} & \multirow[b]{2}{*}{$\begin{array}{l}\% \\
\text { Difference }\end{array}$} & \multicolumn{2}{|c|}{$\begin{array}{c}\text { Average Absorbance } \\
\text { Values }\end{array}$} & \multirow[b]{2}{*}{$\begin{array}{l}\% \\
\text { Difference }\end{array}$} \\
\hline & $\begin{array}{l}\text { Pre } \\
\text { Digestion }\end{array}$ & $\begin{array}{l}\text { Post } \\
\text { Digestion }\end{array}$ & & $\begin{array}{l}\text { Pre } \\
\text { Digestion }\end{array}$ & \begin{tabular}{|l|} 
Post \\
Digestion \\
\end{tabular} & \\
\hline Polymer $(1 \mathrm{mg} / \mathrm{L})$ & 0.15 & 0.16 & -8.28 & 0.30 & 0.32 & -5.80 \\
\hline Polymer $(2.5 \mathrm{mg} / \mathrm{L})$ & 0.13 & 0.17 & -33.77 & 0.27 & 0.33 & -21.65 \\
\hline Polymer $(5 \mathrm{mg} / \mathrm{L})$ & 0.11 & 0.21 & -97.87 & 0.22 & 0.42 & -85.59 \\
\hline Polymer $(7.5 \mathrm{mg} / \mathrm{L})$ & 0.10 & 0.16 & -58.91 & 0.22 & 0.30 & -37.65 \\
\hline Polymer (10 mg/L) & 0.12 & 0.16 & -29.67 & 0.25 & 0.29 & -14.46 \\
\hline No Polymer & 0.16 & 0.15 & 3.33 & 0.31 & 0.29 & 7.16 \\
\hline
\end{tabular}

One explanation for this was that the polymer was partially degraded under anaerobic conditions. This decreases the efficiency of the polymer and, hence, more suspended solids are released into the wastewater which increases the absorption value of the waste water. Chang (2001) conducted experiments to anaerobically digest polymer. Results showed that the polymer was partially degraded under anaerobic conditions. The cationic pendant group was removed by ester hydrolysis which leaves an acrylamide or acrylate monomer within the main polymer chain. It seemed that the portion that was removed had been completely degraded anaerobically. The partial degradation shown in 
the experiment was consistent with the previous studies that suggest only partial degradation of polymer was possible. Dentel et al. (2000) stated that portions of the polymer structure were degraded during anaerobic digestion but the backbone chain appeared to remain intact and remain in the system.

When the polymer breaks down it undergoes hydrolysis and ammonia was released from the amide groups in PAM, ( $\mathrm{Lu}$ and $\mathrm{Wu} 2003$ ). To further validate this, the concentration of ammonia was detected from the wastewater samples before and after digestion. TABLE $\mathrm{X}$ below gives the concentration of ammonia in the waste water before and after anaerobic digestion.

\section{TABLE X}

CONCENTRATION OF AMMONIA BEFORE AND AFTER DIGESTION

\begin{tabular}{|l|r|r|r|}
\hline \multicolumn{4}{|c|}{ Concentration of Ammonia } \\
\hline Reactor & Initial $(\mathrm{mg} / \mathrm{L})$ & Final $(\mathrm{mg} / \mathrm{L})$ & Digestion \% \\
\hline PAM $(1 \mathrm{mg} / \mathrm{L})$ & 0.35 & 0.39 & 11.83 \\
\hline PAM $(2.5 \mathrm{mg} / \mathrm{L})$ & 0.25 & 0.35 & 36.58 \\
\hline PAM $(5 \mathrm{mg} / \mathrm{L})$ & 0.19 & 0.34 & 72.73 \\
\hline PAM $(7.5 \mathrm{mg} / \mathrm{L})$ & 0.15 & 0.32 & 110.90 \\
\hline PAM $(10 \mathrm{mg} / \mathrm{L})$ & 0.17 & 0.31 & 82.35 \\
\hline No PAM & 0.29 & 0.30 & 3.04 \\
\hline No Substrate & 0.07 & 0.06 & -20.51 \\
\hline
\end{tabular}

The concentration of ammonia in the wastewater increased, which supports the theory that the polymer undergoes hydrolysis and ammonia was released. This shows the partial degradation of PAM and why the absorbance values were higher for the post digestion wastewater samples. 


\section{F. ECONOMIC ANALYSIS}

Wastewater from MSD was used for the respirometer experiments. The daily flow data was used to calculate electricity generation potential values. TABLE XI below lists the COD content, the digestibility of the COD, and the potential for MW electric power from methane gas generation for each wastewater sample dosed with varying polymer concentrations. Conversion of methane to electricity was $33 \%$ for a gas fired combustion turbine and $50 \%$ for a base load combined cycle. So, for our calculation purposes the conversion efficiency of methane gas to electricity was assumed to be at $40 \%$.

\section{TABLE XI}

THEORETICAL ELECTRICITY GENERATION VALUES AS A FUNCTION OF PAM CONCENTRATION

\begin{tabular}{|l|c|r|r|r|c|c|c|c|}
\hline Reactor & Flow & COD & COD & Digestion & $\begin{array}{l}\text { Methane } \\
\text { Production }\end{array}$ & \multicolumn{3}{|c|}{$\begin{array}{l}\text { Theoretical Electricity } \\
\text { Generation }\end{array}$} \\
\hline & gal/day & mg/L & lb/day & $\%$ & scf/day & BTU/day & KWhrs/yr & MW \\
\hline $\begin{array}{l}\text { PAM } \\
(1 \mathrm{mg} / \mathrm{L})\end{array}$ & $2,838,800$ & 2376 & 56,290 & 52.73569 & $1.67 \mathrm{E}+05$ & $1.67 \mathrm{E}+08$ & $5.35 \mathrm{E}+06$ & 0.61 \\
\hline $\begin{array}{l}\text { PAM } \\
(2.5 \mathrm{mg} / \mathrm{L})\end{array}$ & $2,838,800$ & 2254 & 53,399 & 41.25998 & $1.24 \mathrm{E}+05$ & $1.24 \mathrm{E}+08$ & $3.97 \mathrm{E}+06$ & 0.45 \\
\hline $\begin{array}{l}\text { PAM } \\
(5 \mathrm{mg} / \mathrm{L})\end{array}$ & $2,838,800$ & 2202 & 52,167 & 43.77838 & $1.28 \mathrm{E}+05$ & $1.28 \mathrm{E}+08$ & $4.12 \mathrm{E}+06$ & 0.47 \\
\hline $\begin{array}{l}\text { PAM } \\
(7.5 \mathrm{mg} / \mathrm{L})\end{array}$ & $2,838,800$ & 2117 & 50,154 & 45.86679 & $1.29 \mathrm{E}+05$ & $1.29 \mathrm{E}+08$ & $4.15 \mathrm{E}+06$ & 0.47 \\
\hline $\begin{array}{l}\text { PAM } \\
(10 \mathrm{mg} / \mathrm{L})\end{array}$ & $2,838,800$ & 1737 & 41,151 & 35.40587 & $8.19 \mathrm{E}+04$ & $8.19 \mathrm{E}+07$ & $2.63 \mathrm{E}+06$ & 0.30 \\
\hline No PAM & $2,838,800$ & 2402 & 56,906 & 54.53789 & $1.74 \mathrm{E}+05$ & $1.74 \mathrm{E}+08$ & $5.60 \mathrm{E}+06$ & 0.64 \\
\hline No Substrate & $2,838,800$ & 702 & 16,631 & 6.410256 & $5.99 \mathrm{E}+03$ & $5.99 \mathrm{E}+06$ & $1.92 \mathrm{E}+05$ & 0.02 \\
\hline
\end{tabular}


The price of electricity is $\$ 0.0682$ cents per KWhr (LG\&E, 2016). TABLE XII below gives a snapshot of the annual electric revenue for each polymer dosage in wastewater and wastewater without polymer.

\section{TABLE XII}

ANNUAL REVENUES FROM ELECTRICITY GENERATION

\begin{tabular}{|l|r|r|}
\hline \multicolumn{1}{|c|}{ Reactor } & Electricity Generation & \multicolumn{1}{c|}{ Annual Revenue } \\
\hline & KWhrs/yr & \\
\hline PAM $(1 \mathrm{mg} / \mathrm{L})$ & $5.35 \mathrm{E}+06$ & $\$ 365,036.12$ \\
\hline PAM $(2.5 \mathrm{mg} / \mathrm{L})$ & $3.97 \mathrm{E}+06$ & $\$ 270,936.62$ \\
\hline PAM $(5 \mathrm{mg} / \mathrm{L})$ & $4.12 \mathrm{E}+06$ & $\$ 280,841.83$ \\
\hline PAM $(7.5 \mathrm{mg} / \mathrm{L})$ & $4.15 \mathrm{E}+06$ & $\$ 282,881.14$ \\
\hline PAM $(10 \mathrm{mg} / \mathrm{L})$ & $2.63 \mathrm{E}+06$ & $\$ 179,167.77$ \\
\hline No PAM & $5.60 \mathrm{E}+06$ & $\$ 381,641.91$ \\
\hline No Substrate & $1.92 \mathrm{E}+05$ & $\$ 13,109.84$ \\
\hline
\end{tabular}

MSD treats 70 tons of dry solids per day. 75.3 pounds of polymer (PAM) was required to treat 1 ton of dry waste. This equates to 5,271 pounds of polymer used per day and $1,923,915$ pounds per year. PAM costs $\$ 0.76$ per pound. This equates to a yearly cost of $\$ 1,462,175$ for polymer. If MSD minimizes the use of polymer and anaerobically digest the wastewater coming out of the centrifuge, there is the potential to save up to $\$ 1,843,817$ per year. 


\section{CONCLUSIONS}

- The analysis and results from the respirometry tests, theoretical biogas comparison, and COD digestion tests all indicate that trace amounts of polymer left in the wastewater after centrifugation, in the range of $2.5 \mathrm{mg} / \mathrm{L}-10 \mathrm{mg} / \mathrm{L}$, can hinder anaerobic digestion of the wastewater.

- The anaerobic digestion tests also indicated that anaerobic digestion is impacted when the residual polymer in the wastewater is greater than $1 \mathrm{mg} / \mathrm{L}$. The biogas production levels and the COD digestion levels of the wastewater dosed with 1 $\mathrm{mg} / \mathrm{L}$ of polymer were similar to the wastewater which had no polymer.

- There was no effect on biogas quality due to trace amounts of polymer, in the $1 \mathrm{mg} / \mathrm{L}-10 \mathrm{mg} / \mathrm{L}$ range, in the wastewater.

- The UV Vis analysis method was not successful in determining the exact amount of trace polymer in the wastewater due to other particles in the wastewater, which interfered with the measurement of the polymer. However, UV Vis can be used indirectly to measure the anaerobic degradation of the trace amounts of polymer in the wastewater based on the clarity of the wastewater

- The wastewater coming out of the centrifuge at the MSD Stream can be anaerobically digested to produce 5.6 million KWhrs per year of electricity which is equivalent to $\$ 381,641$ in electricity charges.

- This study concluded that if MSD minimized the use of polymer and, instead, anaerobically digest the wastewater coming out of the centrifuge, it could lead to a potential yearly savings of up to $\$ 1,843,817$. 


\section{RECOMMENDATIONS}

- Bench scale and lab scale systems are important in early stage analysis. Both are easier to set up and are very cost effective. The respirometer anaerobic digestion tests provide an early snap shot of the impact of trace coagulant polymer in wastewater on anaerobic digestion. It is recommended that this study is replicated on a pilot scale or industrial scale to assess the true impact of polymer on anaerobic digestion.

- The results and analysis of this study on the effect of polymer on wastewater were based on a single type of polymer, Clarifloc CE-1063. This is a high charge cationic polyacrylamide in emulsion form. It is recommended that this study be replicated with other polymers which are used for liquid-solid separation in wastewater facilities.

- UV-Vis method was used for the quantification and characterization of the polymer in the wastewater. This method was not successful due to the interference of other particles in the wastewater. A new reliable and quick method must be developed to measure the amount of trace polymer in the wastewater. Radioactive labeling method of quantification shows promise, but this method can be time consuming and labor intensive.

- This study recommends MSD to avoid the use of polymer and anaerobically digest the wastewater coming out of the centrifuge. This could lead to a potential yearly savings of up to $\$ 1.8$ million. 


\section{REFERENCES CITED}

Aghamir-Baha, S. 2014. Measurement of Polymer Concentration and Optimization of Sludge Dewatering Using UV-VIS Spectroscopy. Master of Science thesis, Carleton University.

Amexander, M. 1965. Biodegradation: Problems of Molecular Recalcitrance and Microbial Fallibility. Advances in Applied Microbiology. 7:35-80.

Amuda, O.S., Amoo, I.A., 2007. Coagulation/flocculation Process and Sludge Conditioning in Beverage Industrial Wastewater Treatment. Journal of Hazardous Materials. 141:778-783.

Budd, S.S., Rao, N.M., Shah, J., Sivakumar, A., 1995. Fluorescent tracer in a water treatment process. USA Patent US5413719A.

Chang, L.L., Raudenbush, D.L., Dentel, S.K., 2001. Aerobic and Anaerobic Biodegradability of a Flocculant Polymer. Water Science and Technology. 44:461-468.

Chu, C.P., Lee, D.J., Chang, B., You, C.H., Liao, C.S., Tay, J.H. 2003. Anaerobic Digestion of Polyelectrolyte Flocculated Waste Activated Sludge. Chemosphere. 53:757-764.

Coeyman, M., 1994. Water Treatment Setting Sights on a Better Year. Chemical week. 154-18:35-36,41.

Dentel, S.K., Chang, L., Raudenbush, D.L., Junnier, R.W., and Abu-Orf, M.M, 2000. Analysis and Fate of Polymers in Wastewater Treatment. Water Environment Research Foundation.

Desai, R., Sahu, O., 2014. Comparative Study of Polymer and Regular Coagulant for Municipal Wastewater Treatment. Journal of Applied Chemistry. 2:82-91.

El-Mamouni, R., Leduc, R., Guiot, S.R., 1998. Influence of Synthetic and Natural Polymers on the Anaerobic Granulation Process. Water Science and Technology. 38-8,9:341-347.

Ghorbanian, M. 2014. Enhancemnet of Anaerobic Digestion of Actual Industrial Wastewaters: Reactor Stability and Kinetic Modeling. PhD Dissertation, University of Louisville. 
Gibbons, M.K., Ormerci, B., 2013. Quantification of Polymer Concentration in Water using UV-Vis spectroscopy. Journal of Water Supply: Research and Technology. 62-4:205-213.

Gossett, J.M., McCarty, P.L., Wilson, J.C., Evans, D.S., 1978. Anaerobic Digestion of Biosolids from Chemical Treatment. Journal of Water Pollution Control Federation. 50:533-542.

Grula, M.M., Huang, M., and Sewell, G. 1994. Interactions of Certain Polyacrylamides with Soil Bacteria. Soil Science. 158:291-300.

Hendrickson, E.R., Neuman, R.D., 1984. Determination of Polyacrylamide by Spectrofluorometry. Analytical Chemistry. 56 (3): 354-357.

Hoadley, K.B., Qi,Y., Thapa, A.F.A., 2011. Application for Filtration Aids for Improving Sludge Dewatering Properties - a review. Chemical Engineering Journal. 171:373-384.

Igoni, A.H., Ayotamuno, M.J., Eze, C.L., Ogaji, S.O.T., Probert, S.D., 2008. Designs of Anaerobic Digesters for Producing Biogas from Municipal Solidwaste. Applied Energy. 85:430-438.

Lu, J., and Wu, L., 2003. Polyacrylamide Quantification Methods in Soil Conservation Studies. Soil and Water Conservation. 58: 270-281

Metcalf and Eddy, Incorporated. 1991. Wastewater Engineering: Treatment Disposal and Reuse. New York: McGraw-Hill.

McCarty, P. 1964. Anaerobic Waste Treatment Fundamentals 9, 107-112. Muller, G., Laine, J.P., Fenyo, J.C., 1979. High Molecular Weight Hydrolyzed Polyacrylamides Characterization Effect on Salts on the conformational properties. Polymer Chemistry. 17 (3): 659-672.

Qasim, S.R. 1998. Wastewater Treatment Plants: Planning, Design and Operation. Second edition. CRC Press, University of Texas Arlington.

Quast, D., 1994. Polymer Optimization in Wastewater Treatment Plants. Products and Applications Seminar, Water Environment Research Foundation (Syracuse, New York).

Rapport, J., Jenkins, B., Zhang, R., Williams, R. 2008. Current Anaerobic Digestion Technologies Used for Treatment of Municipal Organic Solid Waste. California integrated waste management board report (Davis, California). 
Schumann, H, and Kunst, S. (1991). Elimination von 14C - Markierten Polyelecktrolyten in Biologischen Abwasserreinigungsprozessen. GasWasserfach, Wasser/Abwasser 132, 376-383.

Soponkanoporn, T., Gehr, R. 1987. Quantitative-determination and Peak Molecular-weight Analysis of Acrylamide-based Polyelectrolytes by Size Exclusion Chromatography. International Journal of Environmental Analytical Chemistry, 29(1-2), 1-14.

Verma, S. 2002. Anaerobic Digestion of Biodegradable Organics in Municipal Solid Wastes. Master of Science thesis, Columbia University.

Yang, Z., Luo, Y., Xu, Z., Zhou, L., Zeng, G., Huang, J., Xiao, Y., Wang. 2011. Effect of Trace Amounts of Polyacrylamide (PAM) on Long-term Performance of Activated Sludge. Journal of Hazardous Materials. 189:69-75.

Young, J.C and Cowan, R.M. 2004. Respirometry for Environmental Science and Engineering, SJ Enterprises, Springdale, AR, U.S.A.

Zaher, U., Cheong, D., Wu, B., Chen, S. 2007. Producing Energy and Fertilizer from Organic Municipal Solid Waste. Washington State Department of ecology report. 
Prathap D. John was born on January $4^{\text {th }}, 1983$ in Dubai, United Arab Emirates.

He graduated from High School from St. Thomas Central School which is located in Trivandrum, Kerala, India in the year 2000. He went on to attend the University of Louisville earning his Bachelors in Chemical Engineering in the year 2006. He worked as an environmental professional in Frankfort, KY and Dubai and Abu Dhabi, U.A.E. before coming back to the University of Louisville to get his Master's Degree in Chemical Engineering in May 2017. 